Review

\title{
Aurora Kinase B Inhibition: A Potential Therapeutic Strategy for Cancer
}

\author{
Naheed Arfin Borah 1,2 (D) and Mamatha M. Reddy 1,2,* $\mathbb{D}$ \\ 1 The Operation Eyesight Universal Institute for Eye Cancer, L.V. Prasad Eye Institute, \\ Bhubaneswar 751024, India; naheed.borah@gmail.com \\ 2 School of Biotechnology, KIIT University, Bhubaneswar 751024, India \\ * Correspondence: mamathamuppidi@gmail.com or mamatha@lvpei.org; Tel.: +91-6743987175
}

Citation: Borah, N.A.; Reddy, M.M.

Aurora Kinase B Inhibition: A Potential Therapeutic Strategy for Cancer. Molecules 2021, 26, 1981. https://doi.org/10.3390/ molecules26071981

Academic Editor: Roberta Bortolozzi

Received: 4 March 2021

Accepted: 23 March 2021

Published: 1 April 2021

Publisher's Note: MDPI stays neutral with regard to jurisdictional claims in published maps and institutional affiliations.

Copyright: (c) 2021 by the authors. Licensee MDPI, Basel, Switzerland. This article is an open access article distributed under the terms and conditions of the Creative Commons Attribution (CC BY) license (https:// creativecommons.org/licenses/by/ $4.0 /$ )

\begin{abstract}
Aurora kinase B (AURKB) is a mitotic serine/threonine protein kinase that belongs to the aurora kinase family along with aurora kinase A (AURKA) and aurora kinase $C$ (AURKC). AURKB is a member of the chromosomal passenger protein complex and plays a role in cell cycle progression. Deregulation of AURKB is observed in several tumors and its overexpression is frequently linked to tumor cell invasion, metastasis and drug resistance. AURKB has emerged as an attractive drug target leading to the development of small molecule inhibitors. This review summarizes recent findings pertaining to the role of AURKB in tumor development, therapy related drug resistance, and its inhibition as a potential therapeutic strategy for cancer. We discuss AURKB inhibitors that are in preclinical and clinical development and combination studies of AURKB inhibition with other therapeutic strategies.
\end{abstract}

Keywords: aurora kinase B (AURKB); cancer; AURKB regulation; AURKB inhibitors; therapy related drug resistance; combination therapy

\section{Introduction}

Aurora kinases (AURKs) are protein serine/threonine kinases consisting of three members in the gene family-aurora kinase A (AURKA), aurora kinase B (AURKB) and aurora kinase $C$ (AURKC) [1]. AURKs are critical regulators of the cell cycle, with AURKA and AURKB playing a key function in mitosis [1], whereas AURKC has a significant role in gametogenesis [2,3]. AURKs have three different domains, of which the kinase domain shares a high degree of homology among all the members [4]. The functions of AURKs are well-defined by their localization and spatio-temporal expression [5] and also the sequence differences in their N-terminal region [4]. Overexpression of AURKs in tumors has been shown to trigger aneuploidy and genomic instability [6] that leads to tumor development, invasion and metastasis. AURKA and its functions have been widely investigated and several reviews were authored to highlight its importance in cancer $[7,8]$. The role of AURKC in cancer is not completely understood and needs further investigations. This review focuses on AURKB, a potential drug target from the AURK gene family.

Aurora kinase $B$ is encoded by the AURKB gene located on chromosome 17 and is also known by other names including AIK2, AIM1, ARK2, AIRK2, IPL1, STK1, STK5 and STK12. AURKB along with other AURKs plays a vital role in the regulation of cell cycle. Phosphorylation of histone $\mathrm{H} 3$ by aurora kinases is essential for chromosome segregation during cell division. Both AURKA and AURKB have been shown to phosphorylate histone $\mathrm{H} 3$ [9]. The role of elevated AURKB in increasing the phosphorylation of histone $\mathrm{H} 3$ on Ser10 and aneuploidy has been elucidated in studies involving Chinese hamster embryo cells exogenously overexpressing AURKB. The function of AURKB in transformation was further demonstrated in vivo by injecting these AURKB overexpressing cells into BALB/c $\mathrm{nu} / \mathrm{nu}$ mice [10]. Induced AURKB expression is also linked to tumorigenesis mediated by H-Ras [11]. 
Based on its overexpression in various tumors, AURKB has emerged as an important drug target. Small molecule inhibitors were designed to specifically inhibit AURKB function in various tumors. In this review, we focus on AURKB and its function and deregulation in tumorigenesis. Further, we discuss AURKB inhibition as a promising therapeutic strategy and AURKB inhibitors that are in different phases of clinical development. Additionally, the use of AURKB inhibitors in combination with other therapeutic targets is discussed.

\section{Structure and Function of AURKB}

AURKB, similar to other members of the aurora kinase gene family, is composed of three domains: (i) N-terminal domain, (ii) kinase domain, and (iii) C-terminal domain [12]. The kinase domain or catalytic domain is highly conserved between all the three members of the aurora family, whereas the N-terminal domain shows a varied degree of sequence dissimilarity that provides selectivity for protein-protein interactions. The kinase domain in AURKB is composed of a $\beta$-stranded lobe on the $\mathrm{N}$-terminal side and an $\alpha$-helical lobe on the $\mathrm{C}$-terminal side. These two lobes are connected together by a hinge region, which permits active kinase conformation [13]. The C-terminal lobe of the kinase domain contains the catalytic T-loop whose auto-phosphorylation at Thr232 results in AURKB activation. AURKB contains three types of degrons; KEN motif, D-box and DAD/A box that are thought to mediate its degradation. The catalytic domain contains D-boxes (reviewed in [14]). The non-catalytic N-terminal domain has a KEN motif and a DAD/A box, whereas the C-terminal domain has a D-box. However, Nguyen et al., has showed that only N-terminal KEN and DAD/A boxes are responsible for AURKB degradation [15] (Figure 1a).

(a)

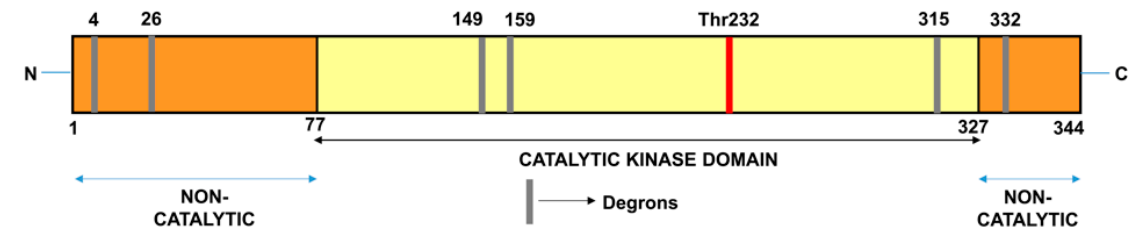

(b)
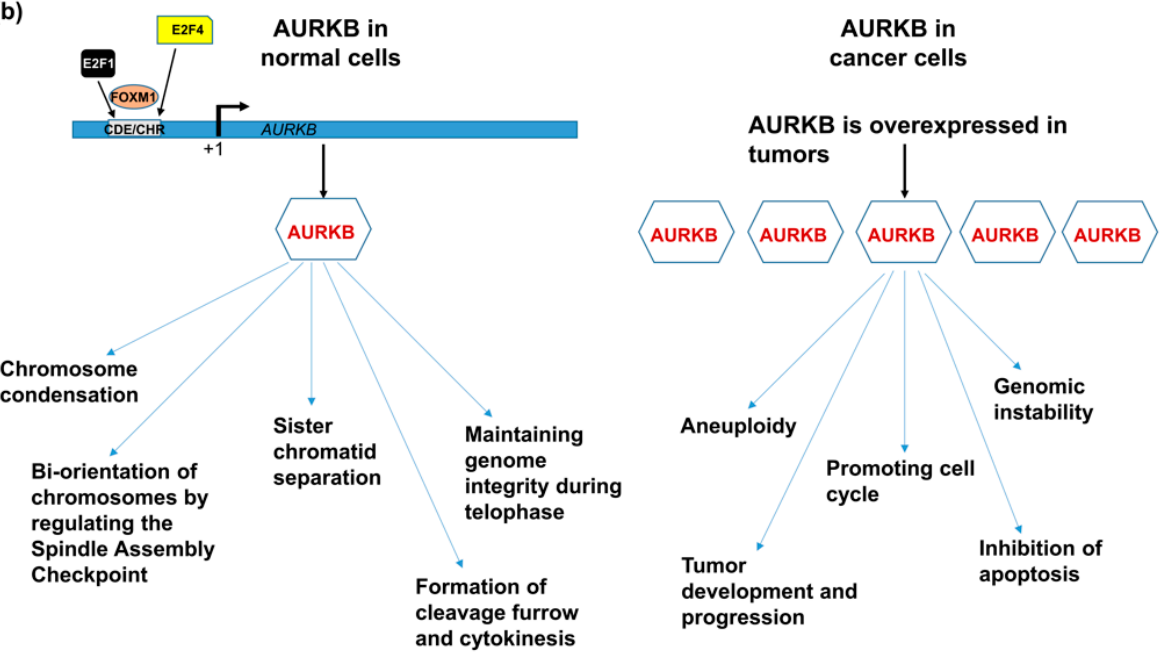

Figure 1. (a) Domain structure of AURKB showing catalytic and non-catalytic domains $[14,16]$. (b) Functions of AURKB in normal cells and cancer cells $[8,14]$.

The binding of E2F1, E2F4, FoxM1 and DP-2 to the AURKB promoter transcriptionally regulates AURKB. These transcription factors bind to the cell cycle-dependent element (CDE) and cell cycle gene homology region (CHR) located up-stream of the transcription start-site (Figure 1b; reviewed in [14]). AURKB is an essential member of the chromosomal passenger complex (CPC) which additionally includes INCENP, survivin 
and borealin $[17,18]$. AURKB is located on the chromatin before the onset of mitosis and promotes chromosome condensation by the phosphorylation of histone $\mathrm{H} 3$ and centrosome protein A (CENP-A) [19]. In pro-metaphase, AURKB, as part of the CPC, moves towards the kinetochores and is associated with repairing faulty spindle kinetochore attachments (spindle assembly checkpoint) [20]. AURKB ensures adequate alignment and segregation of sister chromatids and relocates to the microtubules during the transition from metaphase to anaphase [21]. AURKB regulates the distribution of Kif-2A and limits Kif-2A-controlled depolymerization of microtubules, thereby, mediating microtubule formation and functioning [22]. AURKB has also been implicated in cytokinesis, explained by its presence at the mid-body during telophase [23-25].

\section{Deregulation of AURKB in Cancer}

Drawing parallels with the functions of AURKB in mitosis, it is anticipated that alterations of AURKB either as amplification or overexpression could provide a proliferative advantage to cancer cells (Figure $1 b$ ). In fact, its role in tumor cell transformation was clarified by overexpressing AURKB in murine epithelial cells. When these AURKB overexpressing cells were injected into nude mice, formation of mammary epithelial tumors was observed along with amplifications and deletions of DNA isolated from these mouse mammary tumors [26]. Over the years, aberrant AURKB expression has been reported in a variety of malignancies including human seminoma [27], and thyroid carcinoma [28]. Using mRNA expression analysis Smith et al., found that AURKB expression is markedly elevated in non-small cell lung carcinoma (NSCLC) in comparison to matched untransformed lung tissues. This study also showed that AURKB overexpression led to poor progression free survival, however overall survival was not affected [29]. In contrast to this finding, a study by Vischioni et al., has found that AURKB expression is significantly associated with older age at diagnosis and reduced overall survival in adenocarcinoma subtype of NSCLC [30]. Likewise, AURKB was found to be induced in the squamous carcinoma subtype of NSCLC and the expression level of AURKB also served as a marker for resistance to paclitaxel, a drug commonly used in the treatment of NSCLC [31]. Similar to NSCLC, metastatic colorectal cancer patients lived significantly shorter when they had high levels of AURKB expression in their tumor tissues [32] and the publicly available databases further showed that increased AURKB expression also correlated significantly with reduced survival in breast cancer patients [33]. AURKB expression has been identified as a prognostic biomarker in glioblastoma [34], gastric cancer [35] and oral cancer [36-38]. AURKB overexpression was found to be increased in prostate cancer tissues compared to healthy controls [39]. Hepatocellular carcinoma tissues also showed significantly elevated mRNA expression of AURKB compared to paired healthy liver tissues and was found to be an independent prognostic marker for tumor invasiveness and prognosis [40]. Pediatric acute lymphoblastic leukemia and acute myeloid leukemia (AML) exhibited high levels of both AURKA and AURKB compared to control bone marrow mononuclear cells; however, the inhibition of AURKB alone resulted in apoptosis suggesting that AURKB is a putative drug target but not AURKA in these hematologic malignancies [41]. Recently, we have shown that AURKB is overexpressed in retinoblastoma compared to adjacent healthy retina and its expression significantly correlated with histological risk factors such as optic nerve and anterior chamber invasion [42]. Additionally, we have retrieved expression data of AURKB from Gene Expression Profiling Interactive Analysis (GEPIA) database [43] for a variety of cancers and compared it to their respective normal tissue counterparts (Figure 2). The above studies demonstrating the overexpression of AURKB in tumors compared to their non-cancerous counterpart tissues suggest the possible therapeutic targeting of AURKB in tumors. 


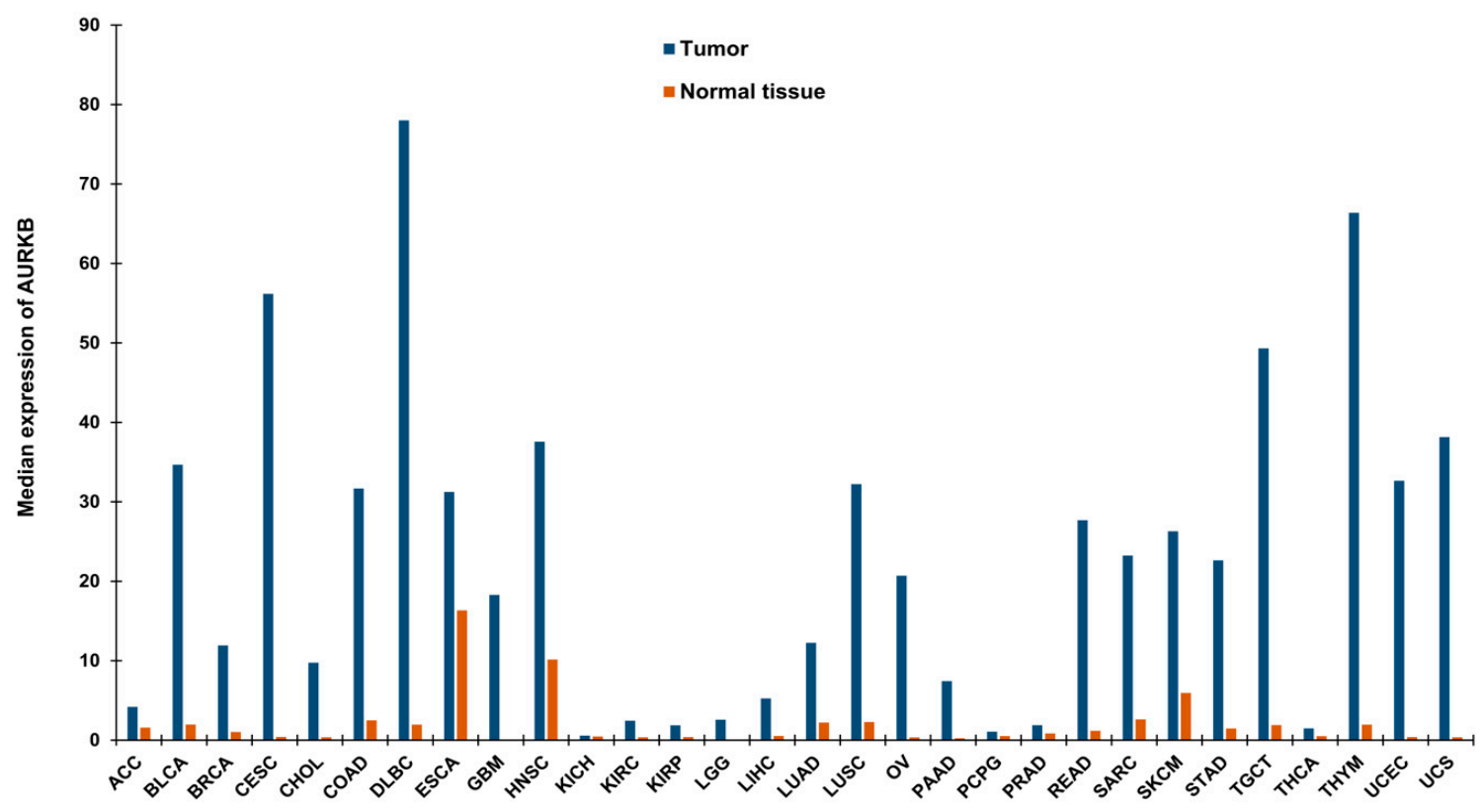

Figure 2. Median expression of AURKB in a variety of tumors and their respective normal tissues. The data has been retrieved from GEPIA [43]. ACC—Adrenocortical carcinoma, BLCA-Bladder Urothelial Carcinoma, BRCA—Breast invasive carcinoma, CESC - Cervical squamous cell carcinoma and endocervical adenocarcinoma, CHOL-Cholangio carcinoma, COAD—Colon adenocarcinoma, DLBC—Lymphoid Neoplasm Diffuse Large B-cell Lymphoma, ESCA—Esophageal carcinoma, GBM-Glioblastoma multiforme, HNSC - Head and Neck squamous cell carcinoma, KICH—Kidney Chromophobe, KIRC — Kidney renal clear cell carcinoma, KIRP—Kidney renal papillary cell carcinoma, LGG—Brain Lower Grade Glioma, LIHC — Liver hepatocellular carcinoma, LUAD_Lung adenocarcinoma, LUSC_Lung squamous cell carcinoma, OV-Ovarian serous cystadenocarcinoma, PAAD—Pancreatic adenocarcinoma, PCPG—Pheochromocytoma and Paraganglioma, PRAD—Prostate adenocarcinoma, READ—Rectum adenocarcinoma, SARC—Sarcoma, SKCM —Skin Cutaneous Melanoma, STAD—Stomach adenocarcinoma, TGCT-Testicular Germ Cell Tumors, THCA-Thyroid carcinoma, THYM-Thymoma, UCEC-Uterine Corpus Endometrial Carcinoma, UCS-Uterine Carcinosarcoma.

\section{Regulation of AURKB Function in Cancer}

Over the years it has been shown that AURKB is overexpressed in various tumors and contributes to tumor development and progression. Several mechanisms underlying the regulation of AURKB and its interactions with other oncogenes or tumor suppressors are currently being explored. AURKB is regulated by upstream activators such as Myc, and cyclin $\mathrm{K}$ and it also regulates functions of certain proteins such as c-Myc and p53.

\subsection{AURKB Regulation by Myc and Vice-Versa}

The Myc oncogenes (c-MYC, MYCN, MYCL) are important determinants of tumor progression in malignancies driven by their overexpression or amplification. den Hollander et al., reported that c-MYC promotes expression of both AURKA and AURKB in c-Myc mediated B-cell lymphoma [44]; however, the regulation of AURKB was rather indirect [44]. In our recent study, we showed enrichment of a MYCN binding motif on the promoter of AURKB in human retinoblastoma and that supports a direct regulation of AURKB by MYCN [42]. Previously, MYCN was shown to be a direct transcriptional regulator of AURKB in neuroblastoma [45]. Interestingly, Jiang et al., delineated that AURKB stabilizes c-MYC in T-cell acute lymphoblastic leukemia (T-ALL) by phosphorylating at Ser67. c-MYC then activates AURKB transcription, creating a positive feedback loop, in turn switching-on a cascade of oncogenic interactions leading to T-cell leukemogenesis [46]. Oncogenes such as MYCN also regulate the expression of a few other dysregulated genes such as enzymes involved in altered metabolism in tumor cells $[47,48]$. 


\subsection{Bcr-Abl Positively Regulates AURKB}

The $\mathrm{Bcr}-\mathrm{Abl}$ oncoprotein is a protein tyrosine kinase associated with chronic myeloid leukemia (CML) and ALL. Yang et al. have reported that Bcr-Abl induces the expression of both AURKA and AURKB through Akt signaling [49].

\subsection{AURKB Crosstalks with BRCA1 and BRCA2}

The inactivation of BRCA1 and/or BRCA2 induces tumor development. Wang et al. described that there is a cross talk between BRCA1/2 and AURKB wherein they inversely control tumor proliferation and tetraploidy of tumor cells. This implies that AURKB disruption leads to a decrease in cell proliferation and cytokinesis whereas disruption in BRCA1/BRCA2 resulted in abnormal cytokinesis, eventually, encouraging tumor progression. It is further considered that this interplay may be through the action of p53 and cyclin A [50].

\subsection{RASSF7 Activates AURKB}

Ras association domain-containing protein 7 (RASSF7) has been previously described as an important mitotic protein and shown to be upregulated in various cancers namely islet cell tumors, ovarian clear cell carcinoma, endometrial cancer and pancreatic ductal carcinoma (reviewed in [51]). Along with activation of AURKB, RASSF7 has a significant contribution in regulating the microtubule cytoskeleton [52]. Further, it was shown that RASSF7 downregulation leads to a loss of AURKB activation in cancer cells [52].

\section{5. $p 53$ Dependent Tumor Suppressor FBXW7 Negatively Regulates AURKB}

F-box and WD repeat containing 7 (FBXW7) protein is a component of the E3 ubiquitin ligase complex and known p53-dependent tumor suppressor [53]. Previously it has been shown that FBXW7 is mutated in breast, bladder and cervical cancers (reviewed in [54]). Mutations or diminished levels of p53 result in increased expression of miR-25, which in turn leads to decreased levels of FBXW7 and the subsequent increase in AURKA levels [55]. Similarly, it was demonstrated that FBXW7 is a negative regulator of AURKB [56].

AURKB in turn suppresses the activity of p53 by phosphorylation at Ser183, Thr211, and Ser215 which quickens its degradation by the proteasome. As a result, the expression of p21Cip1, which is a known cell cycle inhibitor and downstream target of p53, goes down. Inhibition of AURKB was shown to restore the expression of p53 and its targets (Figure 3a) [57]. The above studies indicate a potential feedback loop between p53, FBXW7 and AURKB.

(a)

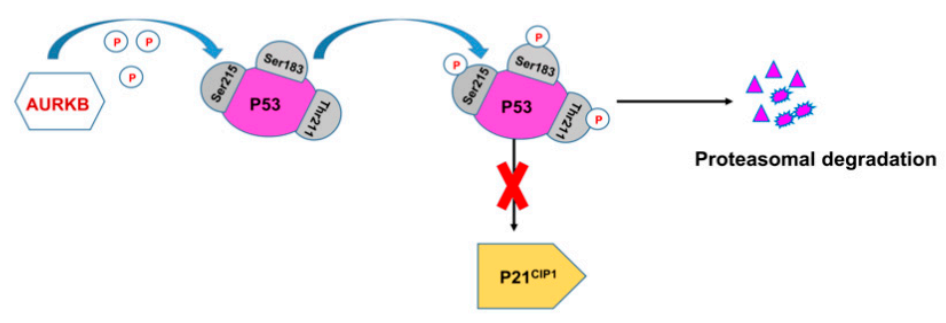

(b)

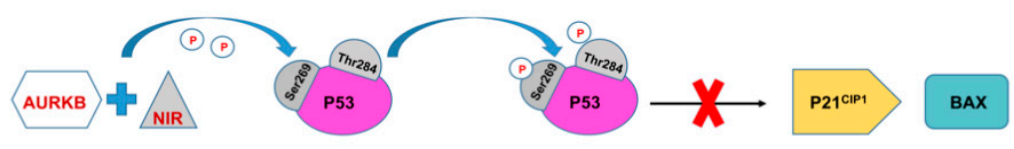

Figure 3. (a) Regulation of p53 by AURKB. (b) p53 regulation by AURKB and novel inhibitor of histone acetyltransferase repressor (NIR).

Additionally, it has been reported that AURKB in association with novel inhibitor of histone acetyltransferase repressor (NIR), phosphorylates p53 at Ser269 or Thr284 and greatly depletes its transcriptional activity, thereby, compromising its downstream targets 
p21 and Bax (Figure 3b) [58]. AURKB also contributes to Epstein-Barr Virus (EBV) induced B-cell oncogenic transformation by downregulating the activity of p53 homolog p73 while functioning along with the latently expressed viral membrane protein, Epstein-Barr nuclear antigen 3C (EBNA3C) [59].

\subsection{AURKB Regulation by MDM2}

MDM2 is an E3 ubiquitin ligase that is shown to be an important oncoprotein in various cancers. MDM2 exerts its functions both through and independent of p53. Recently, using PCR array experiments and MDM2 inhibitor Nutlin-3, it was observed that MDM2 modulates cell cycle possibly through AURKB-CDK1 signaling pathway [60].

\subsection{AURKB Is a Downstream Target of Cyclin K in Prostate Cancer}

Cyclin $\mathrm{K}$ is a member of the cyclin family of transcription regulators which function by association with cyclin dependent kinases. In prostate cancer, cyclin $\mathrm{K}$ was shown to mediate proliferation and inhibit apoptosis likely through AURKB [61].

\section{Targeting AURKB in Cancer}

Deregulated expression of AURKs is increasingly viewed as a potential drug target. AURKs are successfully inhibited in several preclinical cell line and animal models. A variety of small molecule inhibitors to target AURKs have been developed and are in different phases of clinical trials. The development of AURKA inhibitors and their progress has been described recently [7]. The possibility of targeting AURKB has gained momentum during last few years.

Taking into account that the members of the aurora kinase family have very high homology in the kinase domain, most small molecule inhibitors developed against aurora kinases have overlapping inhibitory activity. Despite this, pioneering collaborations between industry and academia led to the development of hesperadin and ZM447439, the former being predominantly selective for AURKB. ZM447439 was further modified to develop AZD1152 [62]. Most of the inhibitors were synthesized with an aim to improve therapy, but over the years, they have been extensively used to understand the varied functions and complex regulations mediated by AURKB. In the following section, we discuss some of the AURKB inhibitors that have high selectivity for AURKB and have undergone clinical trials.

\subsection{AURKB Specific Inhibitors \\ 5.1.1. Hesperadin}

Hesperadin is an indolinone-based ATP-competitive AURKB inhibitor with an $\mathrm{IC}_{50}$ of $250 \mathrm{nM}$ in cell free assays [63]. The indolinone moiety of hesperadin binds to the catalytic cleft of the active enzyme. The forces of interaction between the two molecules are through hydrogen bonding and van-der Waals contact [64]. Further research on hesperadin analogues has revealed that additional hydrogen bonding by lipophilic substitution in the indolinone core could confer enhanced stability and activity to the drug [65]. It has been previously shown that hesperadin causes abnormal mitosis and impairment in cytokinesis. HeLa cells treated with hesperidin do not proliferate and become polyploid in nature [65].

\subsubsection{Barasertib}

Barasertib is an ATP-competitive AURKB inhibitor developed by optimizing ZM447439. It is also known as AZD1152, AZD1152-HQPA and AZD2811. The novel acetanilidesubstituted pyrazole-aminoquinazoline prodrug efficiently gets converted to the active form AZD1152-hydroxyquinazoline pyrazol anilide (AZD1152-HQPA) that lacks the phosphate group found in the pro drug. Barasertib is highly selective for AURKB with an $\mathrm{IC}_{50}$ value of $0.37 \mathrm{nM}$ in cell free assays. It shows a 1000-fold more selectivity for AURKB when compared with AURKA [16]. Over the years, barasertib has been extensively tested in a variety of tumors and has emerged as a lead therapeutic molecule. 
Barasertib has been shown to inhibit cell proliferation, induce polyploidy and subsequently increase apoptosis in AML cell lines. Also, the efficacy of chemotherapy agents was potentiated by AZD1152 in murine xenograft models [66]. Moreover, barasertib was used to target AURKB in NSCLC that had acquired resistance to anti-EGFR therapy [67]. In small cell lung cancer (SCLC) with high amplification of the MYC family proteins, AZD1152 inhibited tumor growth in-vivo [68]. Further, AURKB inhibition by AZD1152 hindered the growth of human lung, colon and hematologic malignancy xenografts in immunodeficient mice [69]. Apart from pre-clinical studies, AZD1152 has been tested in a number of clinical trials to study its efficacy and safety profile predominantly in AML. A study conducted in Japanese patients reported an overall hematologic response rate of $19 \%$. This was a promising result considering no dose limiting toxicities were reported with neutropenia and febrile neutropenia being the most common adverse events [70]. Further, the pharmacokinetics, metabolism and excretion of barasertib was assessed and it was reported that the rate of clearance was slow, and the drug was excreted mostly through feces [71].

A study comparing the responses of barasertib and low dose of cytosine arabinoside (LDAC) as monotherapy was conducted on AML patients. LDAC has been shown to have therapeutic benefits in patients unable to go through intensive chemotherapy. The primary endpoint of the study was the objective complete response rate (OCRR), which is defined as the proportion of patients reaching complete response (CR). A CR is measured according to the criteria established by the international working group for AML trials [72]. Treatment with barasertib showed a significant improvement in OCRR $(35.4 \%)$ in comparison to LDAC (11.5\%). The median overall survival for barasertib was found to be 8.2 months vs 4.5 months for LDAC. This study has shown that barasertib treatment was beneficial, albeit with an increased but manageable toxicity [73]. A combination treatment of barasertib with LDAC was performed in 22 patients with AML. An overall response rate of $45 \%$ $(n=10 / 22)$ was achieved with two patients reporting dose limiting toxicities [74].

Additionally, barasertib was tested on patients with solid tumors and in relapsed/refractory diffuse B-cell lymphoma [NCT01354392]. In case of solid tumors, neutropenia was reported as the most common dose-limiting toxicity and the toxicity profile was found to be tolerable. The recorded responses were at best modest $[75,76]$. The report on B-cell lymphoma described that AZD1152 induced a short-lived reduction in tumor. However, the combination of inconvenience in administering the drug and modest responses did not warrant further investigation of AZD1152 in the treatment of B-cell lymphoma [77].

Overall, the clinical trials established the proof-of concept that AURKB could possibly be targeted with AZD1152 (Table 1). Majority of the reports suggested a positive response to the treatment and a manageable toxicity profile with neutropenia being the most common adverse event, but, it is also known that barasertib at higher concentrations inhibits FLT3 and KIT kinases required for hematopoiesis and hence may result in dose-limiting neutropenia $[78,79]$. However, the mode of administering the drug, which is intravenous infusion for a period of 4 days in diffuse B-cell lymphoma [77] and 7 days for AML [80], has made it highly inconvenient. This led to the development of AZD2811(formerly known as AZD1152) nanoparticle formulation which exceeded the anti-tumor activity reported for AZD1152 drug alone. The improved activity of the nanoparticle formulation was attributed to increased inhibition of phospho-histone H3, polyploidy and apoptosis [80,81]. The details of the clinical trials with AZD2811 nanoparticle formulation are included in Table 1. The IC50s of various cell lines [82-91] that have been tested with AZD1152 are included in Table S1. 
Table 1. List of clinical trials with AURKB inhibitors. Part of the data for the clinical trials have been extracted from clinicaltrials.gov (accessed on 29 March 2021).

\begin{tabular}{|c|c|c|c|c|c|c|c|}
\hline S1. No. & Drug & Study & Tumor & Phase & Sponsored by & Remarks & $\begin{array}{c}\text { References/Clinical } \\
\text { Trials.Gov } \\
\text { Identifier }\end{array}$ \\
\hline 1 & AZD1152 & $\begin{array}{c}\text { A Phase I, Open } \\
\text { Label, } \\
\text { Multi-centre } \\
\text { Study to Assess } \\
\text { the Safety, } \\
\text { Tolerability, and } \\
\text { Pharmacokinetics } \\
\text { of AZD1152 in } \\
\text { Japanese Patients } \\
\text { With Acute } \\
\text { Myeloid } \\
\text { Leukaemia. }\end{array}$ & Leukemia & 1 & $\begin{array}{c}\text { AstraZeneca } \\
\text { (Cambridge, UK) }\end{array}$ & $\begin{array}{c}\text { Promising } \\
\text { response rate of } \\
19 \% \\
\text { (3/16 patients) } \\
\text { indicating the } \\
\text { requirement of } \\
\text { additional } \\
\text { studies. }\end{array}$ & $\begin{array}{c}{[70] /} \\
\text { NCT00530699 }\end{array}$ \\
\hline 2 & AZD1152 & $\begin{array}{l}\text { A Phase } 2 \text { Trial of } \\
\text { AZD1152 in Re- } \\
\text { lapsed/Refractory } \\
\text { Diffuse Large } \\
\text { B-cell Lymphoma }\end{array}$ & Lymphoma & 2 & $\begin{array}{c}\text { Oxford } \\
\text { University } \\
\text { Hospitals NHS } \\
\text { Trust (Oxford, } \\
\text { England) }\end{array}$ & $\begin{array}{l}\text { Although, } \\
\text { AURKB appears } \\
\text { to be a valid } \\
\text { target, the } \\
\text { relatively low } \\
\text { responses and } \\
\text { difficulty in } \\
\text { administering } \\
\text { makes AZD1152 } \\
\text { an unsuitable } \\
\text { candidate for } \\
\text { monotherapy. }\end{array}$ & $\begin{array}{c}{[77] /} \\
\text { NCT01354392 }\end{array}$ \\
\hline
\end{tabular}

\begin{tabular}{|c|c|c|c|c|c|c|c|}
\hline 3 & AZD1152 & $\begin{array}{c}\text { A Phase I, } \\
\text { Open-Label, } \\
\text { Multi-Centre } \\
\text { Study to Assess } \\
\text { the Safety, } \\
\text { Tolerability and } \\
\text { Pharmacokinetics } \\
\text { of AZD1152 } \\
\text { Given as a 2-h or } \\
\text { 48-h Intravenous } \\
\text { Infusions in } \\
\text { Patients With } \\
\text { Advanced Solid } \\
\text { Malignancies }\end{array}$ & Solid tumors & 1 & AstraZeneca & $\begin{array}{c}\text { Manageable } \\
\text { tolerance with } \\
\text { neutropenia and } \\
\text { leukopenia. }\end{array}$ & $\begin{array}{c}{[76] /} \\
\text { NCT00338182 }\end{array}$ \\
\hline 4 & AZD1152 & $\begin{array}{l}\text { A Phase I Open, } \\
\text { Non-randomised, } \\
\text { Single-centre } \\
\text { Study to Assess } \\
\text { the Metabolism, } \\
\text { Excretion and } \\
\text { Pharmacokinetics } \\
\text { of AZD1152 and } \\
\text { AZD1152 hQPA } \\
\text { Following } \\
\text { Intravenous } \\
\text { Administration of } \\
\text { [14C]-AZD1152 in } \\
\text { Patients With } \\
\text { Acute Myeloid } \\
\text { Leukaemia } \\
\text { (AML) }\end{array}$ & Leukemia & 1 & AstraZeneca & $\begin{array}{l}\text { The drug was } \\
\text { well tolerated in } \\
\text { the tested } \\
\text { population and } \\
\text { excreted via } \\
\text { hepatic metabolic } \\
\text { routes. Potential } \\
\text { benefits can be } \\
\text { achieved with } \\
\text { further } \\
\text { investigations. }\end{array}$ & $\begin{array}{c}{[71] /} \\
\text { NCT01019161 }\end{array}$ \\
\hline
\end{tabular}


Table 1. Cont.

\begin{tabular}{|c|c|c|c|c|c|c|c|}
\hline S1. No. & Drug & Study & Tumor & Phase & Sponsored by & Remarks & $\begin{array}{c}\text { References/Clinical } \\
\text { Trials.Gov } \\
\text { Identifier }\end{array}$ \\
\hline 5 & AZD1152 & $\begin{array}{c}\text { A Phase I/II, } \\
\text { Open Label, } \\
\text { Multi-centre } \\
\text { Study to Assess } \\
\text { the Safety, } \\
\text { Tolerability, } \\
\text { Pharmacokinetics } \\
\text { and Efficacy of } \\
\text { AZD1152 in } \\
\text { Patients With } \\
\text { Acute Myeloid } \\
\text { Leukaemia. }\end{array}$ & Leukemia & 1 & AstraZeneca & $\begin{array}{l}\text { A manageable } \\
\text { toxicity profile } \\
\text { was observed } \\
\text { with a response } \\
\text { rate of } 25 \%\end{array}$ & $\begin{array}{c}{[92] /} \\
\text { NCT00497991 }\end{array}$ \\
\hline 6 & AZD1152 & $\begin{array}{c}\text { A Phase I, } \\
\text { Open-label, } \\
\text { Multi-centre, } \\
\text { Multiple } \\
\text { Ascending Dose } \\
\text { Study to Assess } \\
\text { the Safety and } \\
\text { Tolerability of } \\
\text { AZD1152 in } \\
\text { Combination } \\
\text { With Low Dose } \\
\text { Cytosine } \\
\text { Arabinoside } \\
\text { (LDAC) in } \\
\text { Patients With } \\
\text { Acute Myeloid } \\
\text { Leukaemia } \\
\text { (AML) }\end{array}$ & Leukemia & 1 & AstraZeneca & $\begin{array}{l}\text { The combination } \\
\text { of Barasertib with } \\
\text { low dose cytosine } \\
\text { arabinoside } \\
\text { showed } \\
\text { acceptable } \\
\text { tolerability with } \\
\text { an overall } \\
\text { response rate of } \\
45 \% \text { at the } \\
\text { maximum } \\
\text { tolerated dose }\end{array}$ & $\begin{array}{c}{[74,93] /} \\
\text { NCT00926731 }\end{array}$ \\
\hline 7 & AZD1152 & $\begin{array}{l}\text { A Randomised, } \\
\text { Open-label, } \\
\text { Multi-centre, } \\
\text { 2-stage, Parallel } \\
\text { Group Study to } \\
\text { Assess the } \\
\text { Efficacy, Safety } \\
\text { and Tolerability of } \\
\text { AZD1152 Alone } \\
\text { and in } \\
\text { Combination } \\
\text { With Low Dose } \\
\text { Cytosine } \\
\text { Arabinoside } \\
\text { (LDAC) in } \\
\text { Comparison With } \\
\text { LDAC Alone in } \\
\text { Patients } \\
\text { Aged } \geq 60 \text { with } \\
\text { Newly Diagnosed } \\
\text { Acute Myeloid } \\
\text { Leukaemia } \\
\text { (AML) }\end{array}$ & Leukemia & $2 / 3$ & AstraZeneca & $\begin{array}{l}\text { AZD1152 shows a } \\
\text { significant } \\
\text { improvement in } \\
\text { response when } \\
\text { compared to } \\
\text { low-dose cytosine } \\
\text { arabinoside with } \\
\text { relatively high } \\
\text { but manageable } \\
\text { safety profile. }\end{array}$ & $\begin{array}{c}{[73,93] /} \\
\text { NCT00952588 }\end{array}$ \\
\hline
\end{tabular}


Table 1. Cont.

\begin{tabular}{|c|c|c|c|c|c|c|c|}
\hline S1. No. & Drug & Study & Tumor & Phase & Sponsored by & Remarks & $\begin{array}{c}\text { References/Clinical } \\
\text { Trials.Gov } \\
\text { Identifier }\end{array}$ \\
\hline 8 & AZD1152 & $\begin{array}{c}\text { A Phase I, } \\
\text { Open-Label, } \\
\text { Multi-Centre } \\
\text { Study to Assess } \\
\text { the Safety, } \\
\text { Tolerability and } \\
\text { Pharmacokinetics } \\
\text { of AZD1152 } \\
\text { Given as a } \\
\text { Continuous 7-Day } \\
\text { Intravenous } \\
\text { Infusion in } \\
\text { Patients With } \\
\text { Advanced Solid } \\
\text { Malignancies }\end{array}$ & Solid tumors & 1 & AstraZeneca & $\begin{array}{l}\text { The study was } \\
\text { discontinued } \\
\text { because of } \\
\text { technical } \\
\text { difficulties in } \\
\text { administering the } \\
\text { drug and lack of } \\
\text { efficacy. } \\
\text { Additionally, the } \\
\text { prescribed } \\
\text { schedule was } \\
\text { inconvenient. }\end{array}$ & $\begin{array}{c}{[76] /} \\
\text { NCT00497679 }\end{array}$ \\
\hline 9 & AZD1152 & $\begin{array}{c}\text { A Phase I, } \\
\text { Open-Label, } \\
\text { Multi-Centre } \\
\text { Study to Assess } \\
\text { the Safety, } \\
\text { Tolerability and } \\
\text { Pharmacokinetics } \\
\text { of AZD1152 } \\
\text { Given as a } 2 \text { Hour } \\
\text { Intravenous } \\
\text { Infusion on Two } \\
\text { Dose Schedules in } \\
\text { Patients With } \\
\text { Advanced Solid } \\
\text { Malignancies }\end{array}$ & Solid tumors & 1 & AstraZeneca & $\begin{array}{l}\text { The study was } \\
\text { terminated } \\
\text { because of lack of } \\
\text { efficacy of } \\
\text { AZD1152 in } \\
\text { monotherapy on } \\
\text { solid tumors at } \\
\text { the time of study }\end{array}$ & $\begin{array}{c}\text { [75]/ } \\
\text { NCT00497731 }\end{array}$ \\
\hline 10 & AZD1152 & $\begin{array}{c}\text { A Phase I/II, } \\
\text { Open-Label, } \\
\text { Multicentre 2-Part } \\
\text { Study to Assess } \\
\text { the Safety, } \\
\text { Tolerability, Phar- } \\
\text { macokinetics, and } \\
\text { Efficacy of } \\
\text { AZD2811 as } \\
\text { Monotherapy or } \\
\text { in Combination in } \\
\text { Treatment-Naïve } \\
\text { or Re- } \\
\text { lapsed/Refractory } \\
\text { Acute Myeloid } \\
\text { Leukaemia } \\
\text { Patients Not } \\
\text { Eligible for } \\
\text { Intensive } \\
\text { Induction } \\
\text { Therapy. }\end{array}$ & Leukemia & $1 / 2$ & AstraZeneca & $\begin{array}{l}\text { The study is } \\
\text { currently in the } \\
\text { recruitment } \\
\text { phase. }\end{array}$ & NCT03217838 \\
\hline
\end{tabular}


Table 1. Cont

\begin{tabular}{|c|c|c|c|c|c|c|c|}
\hline S1. No. & Drug & Study & Tumor & Phase & Sponsored by & Remarks & $\begin{array}{c}\text { References/Clinical } \\
\text { Trials.Gov } \\
\text { Identifier }\end{array}$ \\
\hline 11 & GSK1070916 & $\begin{array}{c}\text { A Cancer } \\
\text { Research UK } \\
\text { Phase I Trial to } \\
\text { Evaluate Safety, } \\
\text { Tolerability, } \\
\text { Pharmacokinet- } \\
\text { ics and } \\
\text { Pharmacody- } \\
\text { namics of } \\
\text { Aurora B } \\
\text { Inhibitor } \\
\text { GSK1070916A } \\
\text { in Patients With } \\
\text { Advanced Solid } \\
\text { Tumors. }\end{array}$ & Solid tumors & 1 & $\begin{array}{c}\text { Cancer Research } \\
\text { UK (London, } \\
\text { UK) }\end{array}$ & $\begin{array}{l}\text { Neutropenia was } \\
\text { the dose limiting } \\
\text { toxicity with } \\
85 \mathrm{mg} / \mathrm{m}^{2} / \text { day } \\
\text { being the maximum } \\
\text { tolerated dose. }\end{array}$ & $\begin{array}{c}{[94] /} \\
\text { NCT01118611 }\end{array}$ \\
\hline 12 & AT9283 & $\begin{array}{l}\text { A Phase I Study } \\
\text { of AT9283 } \\
\text { Given As a 24-h } \\
\text { Infusion on } \\
\text { Days } 1 \text { and } 8 \\
\text { Every Three } \\
\text { Weeks in } \\
\text { Patients with } \\
\text { Advanced } \\
\text { Incurable } \\
\text { Malignancy }\end{array}$ & $\begin{array}{l}\text { Non- } \\
\text { Hodgkin's } \\
\text { lymphoma } \\
\text { and solid } \\
\text { tumors }\end{array}$ & 1 & $\begin{array}{l}\text { NCIC Clinical } \\
\text { Trials group } \\
\text { (Kingston, } \\
\text { Canada) }\end{array}$ & $\begin{array}{l}\text { AT9283 showed } \\
\text { manageable } \\
\text { tolerability with } \\
\text { recommended } \\
\text { phase } 2 \text { dose at } \\
40 \mathrm{mg} / \mathrm{m}^{2} / \text { day } \\
\text { given on day } 1 \text { and } \\
8 \text { every } 21 \text { days. } \\
\text { The dose limiting } \\
\text { toxicity was febrile } \\
\text { neutropenia. }\end{array}$ & $\begin{array}{c}{[95] /} \\
\text { NCT00443976 }\end{array}$ \\
\hline 13 & AT9283 & $\begin{array}{c}\text { A Phase II } \\
\text { Study of AT9283 } \\
\text { in Patients with } \\
\text { Relapsed or } \\
\text { Refractory } \\
\text { Multiple } \\
\text { Myeloma }\end{array}$ & $\begin{array}{l}\text { Multiple } \\
\text { myeloma }\end{array}$ & 2 & $\begin{array}{l}\text { NCIC Clinical } \\
\text { Trials group }\end{array}$ & $\begin{array}{l}\text { The study reports } \\
\text { that the dose and } \\
\text { schedule of AT9283 } \\
\text { used in the study is } \\
\text { not recommended } \\
\text { for further } \\
\text { investigation for the } \\
\text { treatment of } \\
\text { multiple myeloma. } \\
\text { Although, aurora } \\
\text { kinases as a } \\
\text { possible drug target } \\
\text { is not ruled out. }\end{array}$ & $\begin{array}{c}\text { [96]/ } \\
\text { NCT01145989 }\end{array}$ \\
\hline 14 & AT9283 & $\begin{array}{c}\text { A Phase I/IIa } \\
\text { Open-label } \\
\text { Study to Assess } \\
\text { the Safety, } \\
\text { Tolerability and } \\
\text { Preliminary } \\
\text { Efficacy of } \\
\text { AT9283, a Small } \\
\text { Molecule } \\
\text { Inhibitor of } \\
\text { Aurora Kinases, } \\
\text { in Patients With } \\
\text { Refractory } \\
\text { Hematological } \\
\text { Malignancies }\end{array}$ & Leukemia & $1 / 2$ & $\begin{array}{c}\text { Astex Pharma- } \\
\text { ceuticals, Inc. } \\
\text { (Pleasanton, CA, } \\
\text { USA) }\end{array}$ & $\begin{array}{l}\text { The study reports } \\
\text { cardiac } \\
\text { tachyarrythmias } \\
\text { and severe } \\
\text { reversible } \\
\text { cardiomyopathy in } \\
\text { addition to other } \\
\text { toxicities associated } \\
\text { with cytotoxic } \\
\text { therapy. Reduction } \\
\text { of leukemic blasts } \\
\text { were observed in } \\
\text { some patients but } \\
\text { this did not lead to } \\
\text { a significant clinical } \\
\text { response. }\end{array}$ & $\begin{array}{c}{[97] /} \\
\text { NCT00522990 }\end{array}$ \\
\hline
\end{tabular}


Table 1. Cont

\begin{tabular}{|c|c|c|c|c|c|c|c|}
\hline $\begin{array}{l}\text { S1. } \\
\text { No. }\end{array}$ & Drug & Study & Tumor & Phase & Sponsored by & Remarks & $\begin{array}{c}\text { References/Clinical } \\
\text { Trials.Gov } \\
\text { Identifier }\end{array}$ \\
\hline 15 & AT9283 & $\begin{array}{c}\text { A Cancer } \\
\text { Research UK } \\
\text { Phase I/IIa Trial } \\
\text { of AT9283 (A } \\
\text { Selective } \\
\text { Inhibitor of } \\
\text { Aurora Kinases) } \\
\text { Given Over } 72 \text { h } \\
\text { Every } 21 \text { Days } \\
\text { Via Intravenous } \\
\text { Infusion in } \\
\text { Children and } \\
\text { Adolescents } \\
\text { Aged } 6 \text { Months } \\
\text { to } 18 \text { Years With } \\
\text { Relapsed and } \\
\text { Refractory Acute } \\
\text { Leukemia }\end{array}$ & Leukemia & 1 & Cancer Research UK & $\begin{array}{l}\text { The study shows } \\
\text { that although } \\
\text { toxicity was } \\
\text { tolerable, there } \\
\text { was no evidence } \\
\text { suggesting } \\
\text { efficacy of } \\
\text { AT9283. }\end{array}$ & $\begin{array}{c}{[98] /} \\
\text { NCT01431664 }\end{array}$ \\
\hline 16 & AT9283 & $\begin{array}{l}\text { A phase I dose } \\
\text { escalation study } \\
\text { of AT9283, a } \\
\text { small } \\
\text { molecule } \\
\text { inhibitor of } \\
\text { aurora kinases, } \\
\text { in patients with } \\
\text { advanced solid } \\
\text { malignancies }\end{array}$ & Solid tumors & 1 & $\begin{array}{l}\text { Astex Therapeutics } \\
\text { Ltd. (Pleasanton, } \\
\text { CA, USA); Cancer } \\
\text { Research UK; } \\
\text { Experimental Cancer } \\
\text { Medicine Centre } \\
\text { (UK); National } \\
\text { Institute for Health } \\
\text { Research Biomedical } \\
\text { Research Centre } \\
\text { (UK) }\end{array}$ & $\begin{array}{l}\text { AT9283 was well } \\
\text { tolerated up to a } \\
\text { maximum } \\
\text { tolerated dose of } \\
27 \mathrm{mg} / \mathrm{m}^{2} / 72 \mathrm{~h} \\
\text { and febrile } \\
\text { neutropenia was } \\
\text { the dose limiting } \\
\text { toxicity. }\end{array}$ & [99] \\
\hline 17 & AT9283 & $\begin{array}{c}\text { A Phase I Trial of } \\
\text { AT9283 (a } \\
\text { Selective } \\
\text { Inhibitor of } \\
\text { Aurora Kinases) } \\
\text { in Children and } \\
\text { Adolescents with } \\
\text { Solid Tumors: A } \\
\text { Cancer Research } \\
\text { UK Study }\end{array}$ & Solid tumors & 1 & $\begin{array}{l}\text { Experimental Cancer } \\
\text { Medicine Network } \\
\text { (UK); Cancer } \\
\text { Research UK; the } \\
\text { Oak Foundation at } \\
\text { The Royal } \\
\text { Marsden Hospital } \\
\text { (London, UK); } \\
\text { National Institute for } \\
\text { Health Research } \\
\text { Biomedical Research } \\
\text { Centres; Children's } \\
\text { Cancer and } \\
\text { Leukemia Group } \\
\text { (Leicester, UK) }\end{array}$ & $\begin{array}{l}\text { AT9283 had } \\
\text { manageable } \\
\text { toxicity and was } \\
\text { well tolerated. }\end{array}$ & $\begin{array}{c}{[100,101] /} \\
\text { NCT00985868 }\end{array}$ \\
\hline 18 & $\begin{array}{c}\text { PHA- } \\
739358\end{array}$ & $\begin{array}{c}\text { An Exploratory } \\
\text { Phase II Study of } \\
\text { PHA-739358 in } \\
\text { Patients With } \\
\text { Multiple } \\
\text { Myeloma } \\
\text { Harbouring the } \\
\text { t }(4 ; 14) \\
\text { Translocation } \\
\text { With or Without } \\
\text { FGFR3 } \\
\text { Expression }\end{array}$ & $\begin{array}{l}\text { Multiple } \\
\text { myeloma }\end{array}$ & 2 & $\begin{array}{c}\text { Nerviano Medical } \\
\text { Sciences (Milan, } \\
\text { Italy) }\end{array}$ & $\begin{array}{l}\text { The study was } \\
\text { terminated due } \\
\text { to low } \\
\text { recruitment rate. }\end{array}$ & NCT00872300 \\
\hline
\end{tabular}


Table 1. Cont.

\begin{tabular}{|c|c|c|c|c|c|c|c|}
\hline Sl. No. & Drug & Study & Tumor & Phase & Sponsored by & Remarks & $\begin{array}{c}\text { References/Clinical } \\
\text { Trials.Gov } \\
\text { Identifier }\end{array}$ \\
\hline 19 & $\begin{array}{l}\text { PHA- } \\
739358\end{array}$ & $\begin{array}{l}\text { A Pilot Phase II } \\
\text { Study of } \\
\text { PHA-739358 in } \\
\text { Patients With } \\
\text { Chronic Myeloid } \\
\text { Leukemia } \\
\text { Relapsing on } \\
\text { Gleevec or c-ABL } \\
\text { Therapy }\end{array}$ & Leukemia & 2 & $\begin{array}{c}\text { Jonsson } \\
\text { Comprehensive } \\
\text { Cancer Center } \\
\text { (Los Angeles, CA, } \\
\text { USA) }\end{array}$ & $\begin{array}{l}\text { Results have not } \\
\text { been reported so } \\
\text { far }\end{array}$ & NCT00335868 \\
\hline 20 & $\begin{array}{c}\text { PHA- } \\
739358\end{array}$ & $\begin{array}{c}\text { A Phase I } \\
\text { Dose-Escalation } \\
\text { Study of } \\
\text { danusertib } \\
\text { (PHA-739358) } \\
\text { Administered as a } \\
\text { 24-h Infusion } \\
\text { With and Without } \\
\text { G-CSF in a } \\
\text { 14-day Cycle in } \\
\text { Patients with } \\
\text { Advanced Solid } \\
\text { Tumors }\end{array}$ & Solid tumors & 1 & $\begin{array}{l}\text { National Cancer } \\
\text { Institute } \\
\text { (Bethesda, MD, } \\
\text { USA) }\end{array}$ & $\begin{array}{l}\text { The study } \\
\text { concluded that it } \\
\text { was safe to } \\
\text { administer } \\
\text { danusertib and } \\
\text { the recommended } \\
\text { phase } 2 \text { dose was } \\
\text { determined. }\end{array}$ & [102] \\
\hline 21 & $\begin{array}{l}\text { PHA- } \\
739358\end{array}$ & $\begin{array}{l}\text { A phase I study } \\
\text { of danusertib } \\
\text { (PHA-739358) in } \\
\text { adult patients } \\
\text { with accelerated } \\
\text { or blastic phase } \\
\text { chronic myeloid } \\
\text { leukemia } \\
\text { and Philadelphia } \\
\text { chromosome- } \\
\text { positive acute } \\
\text { lymphoblastic } \\
\text { leukemia } \\
\text { resistant or } \\
\text { intolerant to } \\
\text { imatinib and/or } \\
\text { other second } \\
\text { generation } \\
\text { c-ABL therapy }\end{array}$ & Leukemia & 1 & $\begin{array}{c}\text { Nerviano } \\
\text { Medical Sciences }\end{array}$ & $\begin{array}{c}\text { Danusertib } \\
\text { treatment had an } \\
\text { acceptable toxicity } \\
\text { profile and could } \\
\text { be a promising } \\
\text { agent for } \\
\text { malignancies } \\
\text { associated with } \\
\text { Bcr-Abl. }\end{array}$ & [103] \\
\hline 22 & $\begin{array}{c}\text { PHA- } \\
739358\end{array}$ & $\begin{array}{l}\text { Randomized } \\
\text { phase II study of } \\
\text { danusertib in } \\
\text { patients with } \\
\text { metastatic } \\
\text { castration- } \\
\text { resistant } \\
\text { prostate cancer } \\
\text { after docetaxel } \\
\text { failure }\end{array}$ & $\begin{array}{l}\text { Prostate } \\
\text { cancer }\end{array}$ & 2 & $\begin{array}{c}\text { Nerviano } \\
\text { Medical Sciences }\end{array}$ & $\begin{array}{c}\text { Drug was } \\
\text { well-tolerated } \\
\text { with neutropenia } \\
\text { being the most } \\
\text { common adverse } \\
\text { event. } \\
\text { Monotherapy } \\
\text { with danusertib } \\
\text { showed minimal } \\
\text { efficacy and } \\
\text { further studies are } \\
\text { recommended. }\end{array}$ & [104]/NCT00766324 \\
\hline
\end{tabular}


Table 1. Cont

\begin{tabular}{|c|c|c|c|c|c|c|c|}
\hline S1. No. & Drug & Study & Tumor & Phase & Sponsored by & Remarks & $\begin{array}{c}\text { References/Clinical } \\
\text { Trials.Gov } \\
\text { Identifier }\end{array}$ \\
\hline 23 & $\begin{array}{l}\text { PHA- } \\
739358\end{array}$ & $\begin{array}{c}\text { Phase I } \\
\text { Pharmacokinetic } \\
\text { and Pharmacody- } \\
\text { namic Study of } \\
\text { the Aurora } \\
\text { Kinase Inhibitor } \\
\text { danusertib in } \\
\text { Patients With } \\
\text { Advanced or } \\
\text { Metastatic Solid } \\
\text { Tumors }\end{array}$ & Solid tumors & 1 & $\begin{array}{c}\text { Nerviano } \\
\text { Medical Sciences }\end{array}$ & $\begin{array}{c}\text { The } \\
\text { recommended } \\
\text { phase } 2 \text { dose was } \\
\text { determined in the } \\
\text { study and } \\
\text { neutropenia was } \\
\text { reported as the } \\
\text { dose limiting } \\
\text { toxicity. However, } \\
\text { it was short } \\
\text { lasting and there } \\
\text { were no reported } \\
\text { non-hematologic } \\
\text { toxicities. }\end{array}$ & [105] \\
\hline 24 & AMG900 & $\begin{array}{l}\text { A Phase } 1 \text { Study } \\
\text { Evaluating the } \\
\text { Safety, } \\
\text { Tolerability, } \\
\text { Pharmacokinetics } \\
\text { and Pharmacody- } \\
\text { namics of Orally } \\
\text { Administered } \\
\text { AMG900 in Adult } \\
\text { Subjects With } \\
\text { Acute Myeloid } \\
\text { Leukemia }\end{array}$ & Leukemia & 1 & $\begin{array}{c}\text { Amgen } \\
\text { (Thousand Oaks, } \\
\text { CA, USA) }\end{array}$ & $\begin{array}{l}\text { The study } \\
\text { reported } \\
\text { manageable } \\
\text { hematologic } \\
\text { toxicities but the } \\
\text { patient response } \\
\text { was modest. Dose } \\
\text { escalation was } \\
\text { hampered due to } \\
\text { prolonged } \\
\text { cytopenias. }\end{array}$ & $\begin{array}{c}{[106] /} \\
\text { NCT01380756 }\end{array}$ \\
\hline 25 & AMG900 & $\begin{array}{c}\text { A Phase 1, } \\
\text { First-in-Human } \\
\text { Study Evaluating } \\
\text { the Safety, } \\
\text { Tolerability, } \\
\text { Pharmacokinetics } \\
\text { and Pharmacody- } \\
\text { namics of Orally } \\
\text { Administered } \\
\text { AMG900 in Adult } \\
\text { Subjects With } \\
\text { Advanced Solid } \\
\text { Tumors }\end{array}$ & Solid tumors & 1 & Amgen & $\begin{array}{l}\text { AMG900 showed } \\
\text { acceptable } \\
\text { tolerance. }\end{array}$ & $\begin{array}{c}{[107] /} \\
\text { NCT00858377 }\end{array}$ \\
\hline 26 & CYC116 & $\begin{array}{c}\text { A Phase I } \\
\text { Pharmacologic } \\
\text { Study of CYC116, } \\
\text { an Oral Aurora } \\
\text { Kinase Inhibitor, } \\
\text { in Patients With } \\
\text { Advanced Solid } \\
\text { Tumors }\end{array}$ & Solid tumors & 1 & $\begin{array}{c}\text { Cyclacel } \\
\text { Pharmaceuticals, } \\
\text { Inc.(Berkeley } \\
\text { Heights, NJ, } \\
\text { USA) }\end{array}$ & $\begin{array}{c}\text { The study was } \\
\text { terminated by the } \\
\text { sponsors }\end{array}$ & NCT00560716 \\
\hline
\end{tabular}


Table 1. Cont

\begin{tabular}{|c|c|c|c|c|c|c|c|}
\hline S1. No. & Drug & Study & Tumor & Phase & Sponsored by & Remarks & $\begin{array}{c}\text { References/Clinical } \\
\text { Trials.Gov } \\
\text { Identifier }\end{array}$ \\
\hline 27 & BI 811283 & $\begin{array}{l}\text { An Open Phase I } \\
\text { Single Dose } \\
\text { Escalation Study } \\
\text { of Two Dosing } \\
\text { Schedules of BI } \\
811283 \\
\text { Administered } \\
\text { Intravenously } \\
\text { Over } 24 \text { h } \\
\text { Continuous } \\
\text { Infusion in } \\
\text { Patients With } \\
\text { Advanced Solid } \\
\text { Tumours With } \\
\text { Repeated } \\
\text { Administration in } \\
\text { Patients With } \\
\text { Clinical Benefit }\end{array}$ & Solid tumors & 1 & $\begin{array}{c}\text { Boehringer } \\
\text { Ingelheim } \\
\text { (Ingelheim am } \\
\text { Rhein, Germany) }\end{array}$ & $\begin{array}{l}\text { The study } \\
\text { demonstrated a } \\
\text { manageable } \\
\text { toxicity profile } \\
\text { with disease } \\
\text { stabilization } \\
\text { recorded for } \\
19 \text { patients. } \\
\text { Although, the } \\
\text { limited } \\
\text { anti-cancer } \\
\text { activity did not } \\
\text { warrant further } \\
\text { development of } \\
\text { the drug as a } \\
\text { monotherapy } \\
\text { agent. }\end{array}$ & $\begin{array}{c}{[108]} \\
\text { NCT00701324 }\end{array}$ \\
\hline 28 & BI 811283 & $\begin{array}{l}\text { An Open Phase } \\
\text { I/IIa Trial to } \\
\text { Investigate the } \\
\text { Maximum } \\
\text { Tolerated Dose, } \\
\text { Safety, Efficacy } \\
\text { and } \\
\text { Pharmacokinetics } \\
\text { of BI 811283 in } \\
\text { Combination } \\
\text { With Cytarabine } \\
\text { in Patients With } \\
\text { Previously } \\
\text { Untreated Acute } \\
\text { Myeloid } \\
\text { Leukaemia } \\
\text { Ineligible for } \\
\text { Intensive } \\
\text { Treatment }\end{array}$ & $\begin{array}{c}\text { Acute } \\
\text { Myeloid } \\
\text { Leukemia }\end{array}$ & 2 & $\begin{array}{l}\text { Boehringer } \\
\text { Ingelheim }\end{array}$ & $\begin{array}{l}\text { An acceptable } \\
\text { safety profile was } \\
\text { demonstrated but } \\
\text { the use of BI } \\
811283 \text { with } \\
\text { LDAC did not } \\
\text { show increased } \\
\text { treatment efficacy } \\
\text { in comparison to } \\
\text { LDAC treatment } \\
\text { in isolation. }\end{array}$ & $\begin{array}{c}{[109]} \\
\text { NCT00632749 }\end{array}$ \\
\hline 29 & AZD2811 & $\begin{array}{c}\text { A Phase I, } \\
\text { Open-Label, } \\
\text { Multicentre Dose } \\
\text { Escalation Study } \\
\text { to Assess the } \\
\text { Safety, } \\
\text { Tolerability, and } \\
\text { Pharmacokinetics } \\
\text { of AZD2811 in } \\
\text { Patients With } \\
\text { Advanced Solid } \\
\text { Tumours. }\end{array}$ & Solid tumors & 1 & AstraZeneca & $\begin{array}{l}\text { The study } \\
\text { determined the } \\
\text { maximum } \\
\text { tolerable dose and } \\
\text { the drug is in } \\
\text { further } \\
\text { investigation }\end{array}$ & $\begin{array}{c}{[110]} \\
\text { NCT02579226 }\end{array}$ \\
\hline
\end{tabular}


Table 1. Cont

\begin{tabular}{|c|c|c|c|c|c|c|c|}
\hline S1. No. & Drug & Study & Tumor & Phase & Sponsored by & Remarks & $\begin{array}{l}\text { References/Clinical } \\
\text { Trials.Gov Identifier }\end{array}$ \\
\hline 30 & AZD2811 & $\begin{array}{l}\text { Phase II, Single-arm } \\
\text { Study of AZD2811 } \\
\text { and Durvalumab } \\
\text { (MEDI4736) } \\
\text { Combination } \\
\text { Therapy in } \\
\text { Relapsed Small Cell } \\
\text { Lung Cancer } \\
\text { Subjects With } \\
\text { c-MYC Expression } \\
\text { [SUKSES-E] }\end{array}$ & $\begin{array}{l}\text { Small cell lung } \\
\text { cancer }\end{array}$ & 2 & $\begin{array}{c}\text { Keunchil Park, } \\
\text { Samsung Medical } \\
\text { Center (Seoul, } \\
\text { South Korea) }\end{array}$ & $\begin{array}{l}\text { The study is in the } \\
\text { recruitment phase }\end{array}$ & NCT04525391 \\
\hline 31 & AZD2811 & $\begin{array}{l}\text { Phase II, Single-arm } \\
\text { Study of AZD } 2811 \\
\text { Monotherapy in } \\
\text { Relapsed Small Cell } \\
\text { Lung Cancer } \\
\text { Patients } \\
\text { [SUKSES-N3] }\end{array}$ & $\begin{array}{l}\text { Small cell lung } \\
\text { cancer }\end{array}$ & 2 & $\begin{array}{c}\text { Samsung Medical } \\
\text { Center }\end{array}$ & $\begin{array}{l}\text { The study was } \\
\text { terminated as the } \\
\text { purpose of the study } \\
\text { was fulfilled earlier. }\end{array}$ & $\begin{array}{c}{[111]} \\
\text { NCT03366675 }\end{array}$ \\
\hline 32 & AZD2811 & $\begin{array}{c}\text { A Phase II } \\
\text { Multicenter, } \\
\text { Open-Label, Single } \\
\text { Arm Study to } \\
\text { Determine the } \\
\text { Efficacy, Safety and } \\
\text { Tolerability of } \\
\text { AZD2811 and } \\
\text { Durvalumab } \\
\text { Combination as } \\
\text { Maintenance } \\
\text { Therapy After } \\
\text { Induction With } \\
\text { Platinum-Based } \\
\text { Chemotherapy } \\
\text { Combined With } \\
\text { Durvalumab, for the } \\
\text { First-Line Treatment } \\
\text { of Patients With } \\
\text { Extensive Stage } \\
\text { Small-Cell Lung } \\
\text { Cancer }\end{array}$ & $\begin{array}{l}\text { Small cell lung } \\
\text { cancer }\end{array}$ & 2 & AstraZeneca & $\begin{array}{l}\text { New study. The } \\
\text { recruitment has not } \\
\text { started yet }\end{array}$ & NCT04745689 \\
\hline 33 & AZD2811 & $\begin{array}{c}\text { A Phase I/II, } \\
\text { Open-Label, } \\
\text { Multicentre 2-Part } \\
\text { Study to Assess the } \\
\text { Safety, Tolerability, } \\
\text { Pharmacokinetics, } \\
\text { and Efficacy of } \\
\text { AZD2811 as } \\
\text { Monotherapy or in } \\
\text { Combination in } \\
\text { Treatment-Naïve or } \\
\text { Re- } \\
\text { lapsed/Refractory } \\
\text { Acute Myeloid } \\
\text { Leukaemia Patients } \\
\text { Not Eligible for } \\
\text { Intensive Induction } \\
\text { Therapy. }\end{array}$ & $\begin{array}{l}\text { Acute Myeloid } \\
\text { Leukemia }\end{array}$ & $1 / 2$ & AstraZeneca & $\begin{array}{l}\text { This is an ongoing } \\
\text { study and the latest } \\
\text { update suggests } \\
\text { good tolerability of } \\
\text { the drug. Dose } \\
\text { escalations are } \\
\text { currently being } \\
\text { planned. }\end{array}$ & $\begin{array}{c}\text { [112] } \\
\text { NCT03217838 }\end{array}$ \\
\hline
\end{tabular}

\subsubsection{SP-96}

This is a quinazoline-based AURKB inhibitor with an $\mathrm{IC}_{50}$ of $0.316 \mathrm{nM}$ and is the first described non-ATP competitive inhibitor against AURKB. It has been shown to inhibit the triple negative breast cancer cell line MDA-MD-468 [78]. SP-96 is 2000-fold more 
selective for AURKB in comparison to FLT3 or KIT. It is known that barasertib at higher concentrations also inhibits FLT3 and KIT $[78,79]$. Both FLT3 and KIT kinases play an important role in hematopoiesis and their inhibition may result in neutropenia as observed in the clinical trials for barasertib. Hence, SP-96 plausibly can reduce the adverse effects caused by barasertib [78].

\subsection{Pan Aurora Kinase Inhibitors in Clinical Trials \\ 5.2.1. GSK1070916}

It is an azaindole-based ATP-competitive inhibitor that is highly selective for AURKB and AURKC with $\mathrm{IC}_{50}$ values of 0.38 and $1.5 \mathrm{nM}$, respectively. It is more than 250 -fold more selective for AURKB when compared with AURKA. The discovery of GSK1070916 was initiated by optimizing a series of 7-azaindole based molecules in which cellular activity was enhanced by introducing a 2-aryl group onto the azaindole. Further, treatment of A549 human lung cancer cell lines with GSK1070916 produced a half-maximal effective concentration of $7 \mathrm{nM}$ [113]. GSK1070916 has been shown to inhibit proliferation of tumor cells in more than 100 human tumor cell lines with IC50 values of $<10 \mathrm{nM}$ [114]. The IC50s of various cell lines tested in pre-clinical studies [115,116] with GSK10710916 have been shown in Table S1. It also shows anti-tumor activity in human tumor xenograft models including breast, colon and lung cancer [114]. A phase 1 clinical trial sponsored by Cancer Research UK has been conducted with GSK1070916 in patients suffering from advanced solid tumors. [NCT01118611]. The maximum tolerated dose was determined to be $85 \mathrm{mg} / \mathrm{m}^{2} /$ day with neutropenia as the dose-limiting toxicity [94].

\subsubsection{Danusertib (PHA-739358)}

Danusertib is a 3-aminopyrazole-derived pan-aurora kinase inhibitor with $\mathrm{IC}_{50} \mathrm{~s}$ of 13, 79 and $61 \mathrm{nM}$ in AURKA, AURKB and AURKC, respectively. It has been shown that danusertib induces apoptosis, cell cycle arrest and autophagy in ovarian cancer cells [117]. Additionally, danusertib can inhibit growth of liver metastases both in vitro and in vivo, in gastroenteropancreatic neuroendocrine tumors [118]. The IC50s of danusertib for various cell lines have been reported [119-127] and summarized in Table S1. A phase 1 clinical trial of danusertib in patients with advanced solid tumors showed satisfactory tolerance with preliminary indications of anti-tumor activity [102].

T315I mutation in Bcr/Abl confers resistance to treatment with Bcr/Abl inhibitors in ALL patients with Philadelphia chromosome (Ph). Fei et al., showed that treatment of $\mathrm{Ph}$ positive ALL cells carrying T315I mutation with danusertib can be an alternate therapeutic strategy, especially for imatinib-, nilotinib- or dasatinib-resistant tumors [128]. A phase 1 clinical trial with 37 patients (22 with advanced stage CML and 15 with Ph positive ALL) was conducted for danusertib. The results showed an acceptable toxicity profile with promising anti-tumor activity [103]. Phase 2 clinical studies have also been conducted for danusertib and details of all the clinical trials have been summarized in Table 1.

\subsubsection{AT9283}

1-Cyclopropyl-3-(3-(5-(morpholinomethyl)-1H-benzo[d]imidazol-2-yl)-1H-pyrazol-4-yl)urea is a pan-aurora kinase inhibitor that shows similar selectivity for AURKA and AURKB with an IC50 of $3 \mathrm{nM}$. AT9283 is also effective against additional kinases such as Janus kinases (JAKs) and Abl (T315I) [129]. It was shown to inhibit AURKB activity, induce endoreduplication, suppress cell proliferation and enhance apoptosis in B-cell non-Hodgkin's lymphoma cell lines. Additionally, AT9283 represses tumor growth in mice xenograft models [130]. Pre-clinical studies with AT9283 have been reviewed in Mills, et al., [131]. A recent report showed that AT9283 exhibits anti-proliferative activity in tyrosine kinase inhibitor resistant CML [132].

A phase 1 trial conducted in advanced malignancies showed that AT9283 was well tolerated, and the recommended dose for phase 2 trial was determined to be $40 \mathrm{mg} / \mathrm{m}^{2} /$ day administered at day 1 and day 8 every 21 days. The dose limiting toxicities were febrile 
neutropenia and neutropenia [95]. A phase 1 trial in leukemia patients reported myocardial infarction, cardiomyopathy, hypertension, pneumonia and multiple organ failure as dose limiting toxicities, thus, suggesting extensive cardiovascular monitoring in further studies [97]. A phase 2 study in multiple myeloma reported that no objective responses were observed in the treated patients. They suggested that AT9283 was not recommended for further study for treating multiple myeloma, but the limitations of the trial could not warrant firm conclusions [96]. Overall, AT9283 showed a manageable toxicity profile in clinical trials but further studies are essential to determine its efficacy in clinical use. The list of clinical trials conducted with AT9283 have been summarized in Table 1. The IC50s of AT9283 in CML cell lines are shown in Table S1. [133]

\subsubsection{AMG900}

AMG900 is N-(4-(3-(2-Aminopyrimidin-4-yl)pyridin-2-yloxy)phenyl)-4-(4-methylthiophen2-yl)phthalazin-1-amine, a highly selective pan-AURK inhibitor with $\mathrm{IC}_{50} \mathrm{~s}$ of 5,4 and $1 \mathrm{nM}$ for AURKA, AURKB and AURKC respectively. It is a phthalazinamine-based compound which competitively inhibits binding of ATP to the active site of aurora kinases [134]. Reports have shown that AMG900 inhibited the growth of glioblastoma cells in vitro ultimately leading to cell cycle arrest and senescence [135]. In MOLM-13 AML cell line, treatment with AMG900 was linked to inhibition of histone H3 phosphorylation, polyploidy and increased apoptosis with the upregulation of p53 [136]. The IC50 concentrations of AMG900 on breast cancer cell lines are shown in Table S1 [137].

In a phase 1 clinical trial with AML patients, the safety and efficacy of AMG900 was investigated. Nausea, diarrhea, febrile neutropenia and fatigue were the most common adverse events with $9 \%$ of patients showing complete response. Additionally, the study reported that patients with higher baseline expression of AURKA, TTK, CDC2, BIRC5 and CCNB1 were more susceptible to showing a positive outcome [106]. In a different phase 1 study, AMG900 was shown to be rapidly absorbed with quick clearance. The maximum tolerated dose was determined with or without granulocyte-colony stimulating factor (G-CSF) and found to be 40 and $25 \mathrm{mg} /$ day, respectively. Overall, AMG900 showed a manageable toxicity when used with G-CSF with neutropenia being the most common adverse event [107].

\subsubsection{CYC116}

CYC116 (4-methyl-5-(2-(4-morpholinophenylamino)pyrimidin-4-yl)thiazol-2-amine) is an orally bioavailable panAURK inhibitor which is derived from $\mathrm{N}$-phenyl-4-(thiazol5-yl) pyrimidin-2-amine with IC $_{50}$ values of 8 and $9.2 \mathrm{nM}$ for AURKA and AURKB, respectively. CYC116 has been shown to suppress histone $\mathrm{H} 3$ phosphorylation and induce polyploidy [138]. A clinical trial for CYC116 was subsequently started in patients with advanced solid tumors but was terminated due to a decision taken by the sponsors Cyclacel Pharmaceuticals, Inc. (Berkeley Heights, NJ, USA) The trial was aimed at examining the safety profile of CYC116 (NCT00560716).

\subsubsection{Other Pan-AURK Inhibitors}

Additionally, PHA680632 [139], reversine [33,140], CCT129202 [141], CCT137690 [142,143], SNS-314 [144], quercetin [145,146] are pan-aurora kinase inhibitors that have been tested in pre-clinical studies. Furthermore, VX-680 [147-149] and BI $811283[108,109]$ are pan-AURK inhibitors that have been studied in clinical trials. VX-680 has been extensively reviewed in Pinel, et al., and Portella, et al., [16,150]. The details of clinical trials with BI 811283 are included in the Table 1 . The $\mathrm{IC}_{50}$ s pertaining to pre-clinical studies with AURKB inhibitors are summarized in Table S1. The structures of the described inhibitors are shown in Figure 4. 


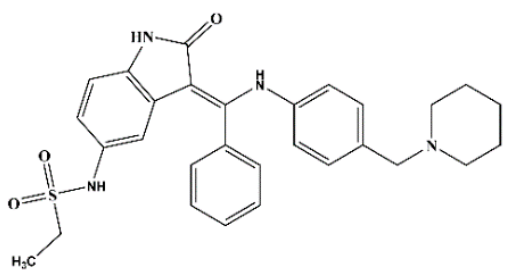

(a) Hesperadin

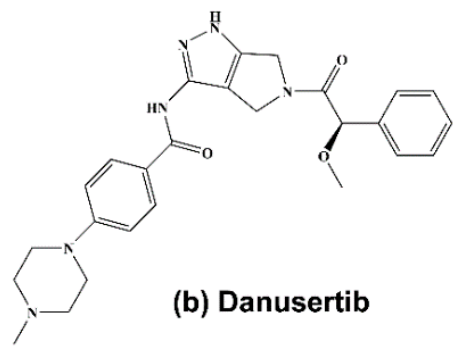

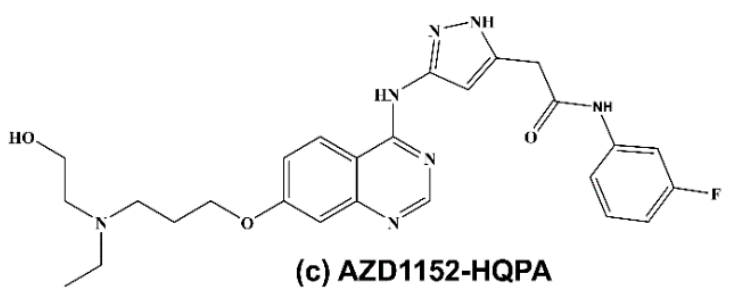<smiles>Cc1nc(N)sc1-c1ccnc(Nc2ccc(N3CCOCC3)cc2)n1</smiles>

(d) CYC116<smiles>O=C(Nc1c[nH]nc1-c1nc2cc(CN3CCOCC3)ccc2[nH]1)NC1CC1</smiles>

(e) AT9283<smiles>CCn1cc(-c2ccnc3[nH]c(-c4cccc(CN(C)C)c4)cc23)c(-c2ccc(NC(=O)C(C)C)cc2)n1</smiles>

(f) GSK1070916

(g) AMG900<smiles>C=C(C)c1cc(C)cs1</smiles>

(h) SP-96<smiles>Cc1csc(-c2nnc(Nc3ccc(Oc4ncccc4-c4ccnc(C)n4)cc3)c3ccccc23)c1</smiles>

Figure 4. Structure of AURKB inhibitors: (a) hesperadin [16], (b) danusertib [151] (c) AZD1152HQPA [152], (d) CYC116 [151], (e) AT9283 [153], (f) GSK1070916 [16], (g) AMG900 [151], (h) SP-96 [78].

\section{Therapy-Related Drug Resistance and AURKB}

Therapy-related drug resistance and the resultant tumor progression are major causes of poor prognosis in various cancers. The resistant tumors usually develop mutations in certain oncogenes or tumor suppressors, or certain genes are expressed at abnormally high levels. AURKB expression has been linked to therapy related drug resistance in different malignancies including vemurafenib-resistant melanoma [154], temozolomide-resistant glioblastoma [154], and epidermal growth factor receptor tyrosine kinase inhibitor-resistant 
NSCLC [67]. Head and neck squamous cell carcinoma cells exhibiting resistance to cetuximab were found to show elevated expression of AURKB on a microarray analysis [155]. Breast cancer cells resistant to the drug fulvestrant showed increased AURKB phosphorylation and AURKB inhibitor barasertib preferentially reduced growth of tumor cells resistant to fulvestrant and tamoxifen [156]. Similarly, MCF7 breast cancer cells resistant to aromatase inhibitors when screened with 195 compounds identified AURKs as novel drug targets. These aromatase resistant breast cancer cells also showed significant growth inhibition when treated with barasertib (specific to AURKB) and JNJ-7706621 (AURKA/B and CDK inhibitor) [157]. Likewise, CML cells resistant to tyrosine kinase inhibition specifically showed reduction in cell proliferation with dual ABL and AURKB inhibitors PHA-739358 and R763/AS703569 [158]. Also, HI-511, a dual inhibitor of AURKB and BRAF V600E achieved drug sensitivity in both susceptible and resistant melanoma cell growth [154]. Overexpression of AURKB in response to various chemotherapeutic drugs suggests that targeting AURKB would be a strategy to overcome therapy-related drug resistance.

On the contrary, mutations in AURKB kinase domain were also identified. T-cell ALL cells were modeled to study the in vitro drug resistance mechanism against AURKB inhibition. When the cells were exposed to high concentrations of ZM447439, a Gly160Glu mutation was observed in the kinase domain of AURKB that could prevent the inhibitor binding in addition to other AURKB independent mechanisms at further high concentrations [159]. Using barasertib-resistant pancreatic carcinoma cell lines and microarray analysis, Guo et al., have shown that elevated expression of multi-drug resistant protein (MDR1) and breast cancer resistant protein (BCRP) is responsible for drug resistance and their expression could serve as a marker for barasertib sensitivity [160].

In some of the studies, it has been shown that AURKB inhibition should not be combined with certain drugs. Treatment with barasertib along with paclitaxel enhanced resistance to paclitaxel treatment in NSCLC cell lines in a dose-dependent manner. In addition, these studies showed that taxanes should not be used if patients express high levels of AURKB [31]. Therefore, expression of AURKB can be used as a predictive biomarker for treatment of NSCLC patients with taxanes.

Using a mutation-prone cell line, Girdler et al., have shown that point mutations can also arise in ATP-binding pocket of AURKB against treatment with AURKB inhibitor ZM447439 [161]. This study suggests that mutations in response to AURKB inhibition might develop similar to other kinase inhibitors and thus additional studies are warranted to understand drug resistance mechanism and subsequent development of novel inhibitors or combination strategies to overcome the therapy-mediated resistance.

\section{Combination Therapy with AURKB Inhibition}

Aurora kinase B inhibition has achieved good in vitro and in vivo efficacy in preclinical models. Currently, some AURKB inhibitors are in clinical trials, but have not yet reached the clinic. The combination studies involving AURKB inhibitors with other anticancer drugs hold promise and efforts were made in that direction using in vitro and in vivo models. The efficacy of AURKB inhibition along with other therapeutic strategies was initially tested using cell line models and the pan-AURK inhibitor VX-680 in combination with chemotherapy drug doxorubicin. VX-680 reduced cell viability of C1A, PC3 and LNCaP cells. The decrease in cell viability was elevated when VX-680 was used in combination with doxorubicin. In addition, VX-680 was shown to sensitize PC 3 cells for treatment with doxorubicin [162]. Another pan-AURK inhibitor CCT137690 demonstrated synergistic anti-oral cancer activity when used in combination with EGFR inhibitor gefitinib or PI-3K inhibitor pictilisib [143]. Subsequently, several studies attempted combination therapies along with AURKB inhibition. Barasertib augmented the therapeutic response of vincristine and daunorubicin in AML cell lines as well as mouse models [66] and a topoisomerase I inhibitor CPT-11 in HCT-116 colorectal carcinoma cells [163]. Combination targeting of AURKB and orally available BH3 mimetic, ABT-263 led to a decrease in cell viability in several different tumor cell lines compared to monotherapy with VX-680. siRNA 
knockdown with AURKA and AURKB further confirmed that synergistic activity was due to inhibition of AURKB [164]. Similar to studies above, AURKB inhibitor barasertib was shown to enhance combination effectiveness of oxaliplatin and gemcitabine in colon and pancreatic cancer respectively [155]. In vitro and in vivo analysis demonstrated that AURKB inhibition along with inhibition of DNA repair protein PARP1 had synergistic activity against skin cutaneous melanoma cells [165]. However, AURKB inhibitor barasertib and cytarabine used in combination exerted a greater-than-additive cytotoxicity in AML cells [166].

Recently, a few other studies attempted to identify the synthetic lethal interactions with AURKB inhibition. One of the studies using CRISPR/Cas9 identified that haspin kinase when inhibited in combination with AURKB inhibition considerably enhanced the antitumor activity in a synthetic lethal manner [147]. A different study using CRISPR/Cas9 parallelly identified that SCLC cells with loss of RB1 tumor suppressor gene are hyperdependent on AURKB for their survival and inhibition with AURKB inhibitors significantly reduced cell proliferation demonstrating that loss of RB1 is synthetic lethal with AURKB inhibition [167]. AURKB inhibition was also found to be synthetic lethal with Myc overexpression $[168,169]$. Similarly, TAK-901, AURKB inhibitor from Takeda Pharmaceuticals showed synthetic lethal activity along with BCL-XL inhibition [170]. Further, loss-of-function RNAi screen identified that AURKB inhibition along with rapamycin had a synergistic activity in breast cancer cell lines [171]. Additional approaches including pharmacological small molecule inhibitor screens were employed to identify combination therapy treatments. One such screen identified synergistic efficacy of AURKB inhibitor Barasertib when combined with focal adhesion kinase inhibitors PF-562271 and VS-4718 to inhibit Ewing's sarcoma cell growth [172].

AT9283 suppresses tumor growth in aggressive B-cell lymphomas and in these cells, it had a potent anti-AURKB activity. When AT9283 was used in combination with a taxane docetaxel, it showed a synergistic anti-tumor activity [130]. On the contrary, AT9283 showed both anti-AURKA and AURKB activity in multiple myeloma cells. The antimyeloma activity of AT9283 was further enhanced in a synergistic manner when used in combination with lenalidomide, a dicarboximide used in the treatment of multiple myeloma [153].

AURKB inhibition in combination with other drugs was successfully tested as a strategy to mitigate therapy-related drug resistance. Inhibition of AURKB using siRNA along with temozolomide enhanced the in vitro chemotherapeutic response of temozolomideresistant glioma cells [173]. Nanoparticles of AURKB siRNA also showed comparable synergistic activity when used in combination with temozolomide in glioblastoma and enhanced survival of orthotopic mouse models of glioblastoma [174]. In a different study, Alafate et al., have performed kinome analysis and identified that AURKB is an important candidate responsible for the chemoresistance in temozolomide-resistant glioblastoma cells and the associated drug resistance could be mitigated by combined targeting of AURKB along with temozolomide [175]. Similarly, inhibition of AURKs enhanced the chemosensitivity to temozolomide and caused radio-sensitization in glioblastoma cells [176]. To incorporate AURKB inhibitors into clinical practice, additional studies involving exhaustive combination therapies should be tested, particularly, for the chemotherapy resistant tumors with elevated levels of AURKB expression.

\section{Computational Chemistry Approaches to Develop Promising Inhibitors for AURKB}

In the last few decades computational chemistry approaches have helped accelerate the process of drug development for various cancers. Molecular docking studies were employed to predict more efficient inhibitors against oncogenic protein kinases including aurora kinases. A recent in-silico analysis using docking-based comparative intermolecular contacts analysis (dbCICA) identified a lead molecule 85 (NCI 14040). The molecule 85 was further validated for its in vitro efficacy against AURKA. The study showed that the compound 85 has activity against pancreas, breast and prostate cancer cell lines [177]. 8-amino-substituted purine-based derivatives were synthesized to inhibit AURKs and 
the in vitro efficacy analysis against various tumor cell lines further identified that breast cancer cell lines were more sensitive compared to other cell lines tested [178]. In a different study, 4-anilinoquinoline derivatives with sulfonamide moiety were synthesized to inhibit AURKA/B. Docking studies were employed to confirm the molecular interactions between the inhibitors and the AURKs. The in vitro analyses identified that compound $9 \mathrm{~d}$ among different synthesized molecules was more effective [179]. Further, Fernandes et al., using the Molegro Virtual Docker (MVD) software identified that IAF79 compound is a promising dual AURKB and FLT3 inhibitor for the treatment against various cancer types particularly for AML [180]. All the above studies highlight the role of computational approaches in drug development, and this specifically speeds up the process for rational drug design.

\section{Conclusions}

Deregulation of cell cycle plays a critical role in tumor initiation, progression, invasion and metastasis and the proteins involved in the regulation of cell cycle including AURKB are overexpressed in various tumors. AURKB promotes tumorigenesis and chemotherapy associated drug resistance. The expression of AURKB is regulated by other proteins such c-Myc, MDM2, MYCN, and cyclin K. Targeting AURKB is increasingly seen as a feasible therapeutic strategy against various tumors. Nevertheless, the currently available AURKB inhibitors though showed in vitro and in vivo therapeutic efficacy, they have not reached the clinic so far. Combination therapy of AURKB inhibition along with other small molecule inhibitors with activity against tumors or traditional chemotherapy agents is the need of the hour and should be pursued rapidly to achieve additional armamentarium in the fight against cancers. Further, several of the AURKB inhibitors have off-target effects on other kinases; and therefore, we need to develop and test more specific AURKB inhibitors for future use in fight against cancer.

Supplementary Materials: The following are available online. Table S1. IC50 values for AURKB inhibitors in preclinical studies.

Author Contributions: Writing—Original Draft Preparation, N.A.B. and M.M.R.; Writing—Review \& Editing, N.A.B. and M.M.R.; Funding Acquisition, M.M.R. All authors have read and agreed to the published version of the manuscript.

Funding: This research was funded by the Innovative Young Biotechnologist Award, Department of Biotechnology, Govt. of India [BT/09/IYBA/2015/10 to MMR] and continuation of Centre of Excellence grant, Department of Biotechnology, Govt. of India [BT/PR32404/MED/30/2136/2019] and the APC was funded by [Hyderabad Eye Research Foundation, LV Prasad Eye Institute, India].

Institutional Review Board Statement: Not applicable.

Informed Consent Statement: Not applicable.

Data Availability Statement: The data for Figure 2 has been extracted from gepia.cancer-pku.cn accessed on 28 March 2021.

Conflicts of Interest: The authors declare no conflict of interest.

\section{References}

1. Nigg, E.A. Mitotic kinases as regulators of cell division and its checkpoints. Nat. Rev. Mol. Cell. Biol. 2001, 2, 21-32. [CrossRef]

2. Dieterich, K.; Soto Rifo, R.; Karen Faure, A.; Hennebicq, S.; Amar, B.B.; Zahi, M.; Perrin, J.; Martinez, D.; Sèle, B.; Jouk, P.S.; et al. Homozygous mutation of AURKC yields large-headed polyploid spermatozoa and causes male infertility. Nat. Genet. 2007, 39, 661-665. [CrossRef] [PubMed]

3. Sharif, B.; Na, J.; Lykke-Hartmann, K.; McLaughlin, S.H.; Laue, E.; Glover, D.M.; Zernicka-Goetz, M. The chromosome passenger complex is required for fidelity of chromosome transmission and cytokinesis in meiosis of mouse oocytes. J. Cell Sci. 2010, 123, 4292-4300. [CrossRef] [PubMed]

4. Carmena, M.; Earnshaw, W.C. The cellular geography of Aurora kinases. Nat. Rev. Mol. Cell Biol. 2003, 4, 842-854. [CrossRef] [PubMed]

5. Li, S.; Deng, Z.; Fu, J.; Xu, C.; Xin, G.; Wu, Z.; Luo, J.; Wang, G.; Zhang, S.; Zhang, B.; et al. Spatial compartmentalization specializes the function of Aurora A and Aurora B. J. Biol. Chem. 2015, 290, 17546-17558. [CrossRef] 
6. Marumoto, T.; Zhang, D.; Saya, H. Aurora-A-A guardian of poles. Nat. Rev. Cancer 2005, 5, 42-50. [CrossRef]

7. Galetta, D.; Cortes-Dericks, L. Promising therapy in lung cancer: Spotlight on aurora kinases. Cancers 2020, 12, 3371. [CrossRef]

8. Tang, A.; Gao, K.; Chu, L.; Zhang, R.; Yang, J.; Zheng, J. Aurora kinases: Novel therapy targets in cancers. Oncotarget 2017, 8, 23937-23954. [CrossRef] [PubMed]

9. Crosio, C.; Fimia, G.M.; Loury, R.; Kimura, M.; Okano, Y.; Zhou, H.; Sen, S.; Allis, C.D.; Sassone-corsi, P. Mitotic Phosphorylation of Histone H3: Spatio-Temporal Regulation by Mammalian Aurora Kinases. Mol. Cell. Biol. 2002, 22, 874-885. [CrossRef] [PubMed]

10. Ota, T.; Suto, S.; Katayama, H.; Han, Z.B.; Suzuki, F.; Maeda, M.; Tanino, M.; Terada, Y.; Tatsuka, M. Increased mitotic phosphorylation of histone $\mathrm{H} 3$ attributable to AIM-1/aurora-B overexpression contributes to chromosome number instability. Cancer Res. 2002, 62, 5168-5177. [PubMed]

11. Kanda, A.; Kawai, H.; Suto, S.; Kitajima, S.; Sato, S.; Takata, T.; Tatsuka, M. Aurora-B/AIM-1 kinase activity is involved in Ras-mediated cell transformation. Oncogene 2005, 24, 7266-7272. [CrossRef]

12. Bolanos-Garcia, V.M. Aurora kinases. Int. J. Biochem. Cell Biol. 2005, 37, 1572-1577. [CrossRef] [PubMed]

13. Cheetham, G.M.T.; Knegtel, R.M.A.; Coll, J.T.; Renwick, S.B.; Swenson, L.; Weber, P.; Lippke, J.A.; Austen, D.A. Crystal structure of Aurora-2, an oncogenic serine/threonine kinase. J. Biol. Chem. 2002, 277, 42419-42422. [CrossRef] [PubMed]

14. Willems, E.; Dedobbeleer, M.; Digregorio, M.; Lombard, A.; Lumapat, P.N.; Rogister, B. The functional diversity of Aurora kinases: A comprehensive review. Cell Div. 2018, 1-17. [CrossRef]

15. Nguyen, H.G.; Chinnappan, D.; Urano, T.; Ravid, K. Mechanism of Aurora-B Degradation and Its Dependency on Intact KEN and A-Boxes: Identification of an Aneuploidy-Promoting Property. Mol. Cell. Biol. 2005, 25, 4977-4992. [CrossRef]

16. Portella, G.; Passaro, C.; Chieffi, P. Aurora B: A New Prognostic Marker and Therapeutic Target in Cancer. Curr. Med. Chem. 2011, 18, 482-496. [CrossRef]

17. Vader, G.; Medema, R.H.; Lens, S.M.A. The chromosomal passenger complex: Guiding Aurora-B through mitosis. J. Cell Biol. 2006, 173, 833-837. [CrossRef]

18. Gassmann, R.; Carvalho, A.; Henzing, A.J.; Ruchaud, S.; Hudson, D.F.; Honda, R.; Nigg, E.A.; Gerloff, D.L.; Earnshaw, W.C. Borealin: A novel chromosomal passenger required for stability of the bipolar mitotic spindle. J. Cell Biol. 2004, 166, 179-191. [CrossRef] [PubMed]

19. Zeitlin, S.G.; Shelby, R.D.; Sullivan, K.F. CENP-A is phosphorylated by Aurora B kinase and plays an unexpected role in completion of cytokinesis. J. Cell Biol. 2001, 155, 1147-1157. [CrossRef] [PubMed]

20. Broad, A.J.; DeLuca, K.F.; DeLuca, J.G. Aurora B kinase is recruited to multiple discrete kinetochore and centromere regions in human cells. J. Cell Biol. 2020, 219. [CrossRef]

21. Yi, Q.; Chen, Q.; Yan, H.; Zhang, M.; Liang, C.; Xiang, X.; Pan, X.; Wang, F. Aurora B kinase activity- dependent and -independent functions of the chromosomal passenger complex in regulating sister chromatid cohesion. J. Biol. Chem. 2019, 294, $2021-2035$. [CrossRef] [PubMed]

22. Uehara, R.; Tsukada, Y.; Kamasaki, T.; Poser, I.; Yoda, K.; Gerlich, D.W.; Goshima, G. Aurora B and Kif2A control microtubule length for assembly of a functional central spindle during anaphase. J. Cell Biol. 2013, 202, 623-636. [CrossRef] [PubMed]

23. Schumacher, J.M.; Golden, A.; Donovan, P.J. AIR-2: An Aurora/Ipl1-related protein kinase associated with chromosomes and midbody microtubules is required for polar body extrusion and cytokinesis in Caenorhabditis elegans embryos. J. Cell Biol. 1998, 143, 1635-1646. [CrossRef] [PubMed]

24. Giet, R.; Glover, D.M. Drosophila aurora B kinase is required for histone H3 phosphorylation and condensin recruitment during chromosome condensation and to organize the central spindle during cytokinesis. J. Cell Biol. 2001, 152, 669-682. [CrossRef] [PubMed]

25. Adams, R.R.; Maiato, H.; Earnshaw, W.C.; Carmena, M. Essential roles of Drosophila inner centromere protein (INCENP) and aurora $\mathrm{B}$ in histone $\mathrm{H} 3$ phosphorylation, metaphase chromosome alignment, kinetochore disjunction, and chromosome segregation. J. Cell Biol. 2001, 153, 865-880. [CrossRef] [PubMed]

26. Nguyen, H.G.; Makitalo, M.; Yang, D.; Chinnappan, D.; St.Hilaire, C.; Ravid, K. Deregulated Aurora-B induced tetraploidy promotes tumorigenesis. FASEB J. 2009. [CrossRef]

27. Chieffi, P.; Troncone, G.; Caleo, A.; Libertini, S.; Linardopoulos, S.; Tramontano, D.; Portella, G. Aurora B expression in normal testis and seminomas. J. Endocrinol. 2004, 181, 263-270. [CrossRef]

28. Sorrentino, R.; Libertini, S.; Pallante, P.L.; Troncone, G.; Palombini, L.; Bavetsias, V.; Spalletti-Cernia, D.; Laccetti, P.; Linardopoulos, S.; Chieffi, P.; et al. Aurora B overexpression associates with the thyroid carcinoma undifferentiated phenotype and is required for thyroid carcinoma cell proliferation. J. Clin. Endocrinol. Metab. 2005, 90, 928-935. [CrossRef]

29. Smith, S.L.; Bowers, N.L.; Betticher, D.C.; Gautschi, O.; Ratschiller, D.; Hoban, P.R.; Booton, R.; Santibáñez-Koref, M.F.; Heighway, J. Overexpression of aurora B kinase (AURKB) in primary non-small cell lung carcinoma is frequent, generally driven from one allele, and correlates with the level of genetic instability. Br. J. Cancer 2005, 93, 719-729. [CrossRef]

30. Vischioni, B.; Oudejans, J.J.; Vos, W.; Rodriguez, J.A.; Giaccone, G. Frequent overexpression of aurora B kinase, a novel drug target, in non-small cell lung carcinoma patients. Mol. Cancer Ther. 2006, 5, 2905-2913. [CrossRef]

31. Al-Khafaji, A.S.K.; Davies, M.P.A.; Risk, J.M.; Marcus, M.W.; Koffa, M.; Gosney, J.R.; Shaw, R.J.; Field, J.K.; Liloglou, T. Aurora B expression modulates paclitaxel response in non-small cell lung cancer. Br. J. Cancer 2017, 116, 592-599. [CrossRef] 
32. Pohl, A.; Azuma, M.; Zhang, W.; Yang, D.; Ning, Y.; Winder, T.; Danenberg, K.; Lenz, H.J. Pharmacogenetic profiling of Aurora kinase B is associated with overall survival in metastatic colorectal cancer. Pharm. J. 2011, 11, 93-99. [CrossRef]

33. Huang, D.; Huang, Y.; Huang, Z.; Weng, J.; Zhang, S.; Gu, W. Relation of AURKB over-expression to low survival rate in BCRA and reversine-modulated aurora B kinase in breast cancer cell lines. Cancer Cell Int. 2019, 19, 1-13. [CrossRef]

34. Zeng, W.F.; Navaratne, K.; Prayson, R.A.; Weil, R.J. Aurora B expression correlates with aggressive behaviour in glioblastoma multiforme. J. Clin. Pathol. 2007, 60, 218-221. [CrossRef]

35. Nie, M.; Wang, Y.; Yu, Z.; Li, X.; Deng, Y.; Wang, Y.; Yang, D.; Li, Q.; Zeng, X.; Ju, J.; et al. AURKB promotes gastric cancer progression via activation of CCND1 expression. Aging 2020, 12, 1304-1321. [CrossRef] [PubMed]

36. Qi, G.; Ogawa, I.; Kudo, Y.; Miyauchi, M.; Siriwardena, B.S.M.S.; Shimamoto, F.; Tatsuka, M.; Takata, T. Aurora-B expression and its correlation with cell proliferation and metastasis in oral cancer. Virchows Arch. 2007, 450, 297-302. [CrossRef] [PubMed]

37. Pannone, G.; Hindi, S.A.H.; Santoro, A.; Sanguedolce, F.; Rubini, C.; Cincione, R.I.; De Maria, S.; Tortorella, S.; Rocchetti, R.; Cagiano, S.; et al. Aurora B expression as a prognostic indicator and possibile therapeutic target in oral squamous cell carcinoma. Int. J. Immunopathol. Pharmacol. 2011, 24, 79-88. [CrossRef]

38. Li, M.; Liu, H.; Zhao, Q.; Han, S.; Zhou, L.; Liu, W.; Li, W.; Gao, F. Targeting Aurora B kinase with Tanshinone IIA suppresses tumor growth and overcomes radioresistance. Cell Death Dis. 2021, 12. [CrossRef]

39. Chieffi, P.; Cozzolino, L.; Kisslinger, A.; Libertini, S.; Staibano, S.; Mansueto, G.; De Rosa, G.; Villacci, A.; Vitale, M.; Linardopoulos, S.; et al. Aurora B expression directly correlates with prostate cancer malignancy and influence prostate cell proliferation. Prostate 2006, 66, 326-333. [CrossRef] [PubMed]

40. Lin, Z.Z.; Jeng, Y.M.; Hu, F.C.; Pan, H.W.; Tsao, H.W.; Lai, P.L.; Lee, P.H.; Cheng, A.L.; Hsu, H.C. Significance of Aurora B overexpression in hepatocellular carcinoma. Aurora B Overexpression in HCC. BMC Cancer 2010, 10. [CrossRef]

41. Hartsink-Segers, S.A.; Zwaan, C.M.; Exalto, C.; Luijendijk, M.W.J.; Calvert, V.S.; Petricoin, E.F.; Evans, W.E.; Reinhardt, D.; De Haas, V.; Hedtjärn, M.; et al. Aurora kinases in childhood acute leukemia: The promise of aurora B as therapeutic target. Leukemia 2013, 27, 560-568. [CrossRef] [PubMed]

42. Borah, N.A.; Sradhanjali, S.; Barik, M.R.; Jha, A.; Tripathy, D.; Kaliki, S.; Rath, S.; Raghav, S.K.; Patnaik, S.; Mittal, R.; et al. Aurora Kinase B Expression, Its Regulation and Therapeutic Targeting in Human Retinoblastoma. Investig. Ophthalmol. Vis. Sci. 2021, 62, 16. [CrossRef] [PubMed]

43. Tang, Z.; Li, C.; Kang, B.; Gao, G.; Li, C.; Zhang, Z. GEPIA: A web server for cancer and normal gene expression profiling and interactive analyses. Nucleic Acids Res. 2017, 45, W98-W102. [CrossRef] [PubMed]

44. Den Hollander, J.; Rimpi, S.; Doherty, J.R.; Rudelius, M.; Buck, A.; Hoellein, A.; Kremer, M.; Graf, N.; Scheerer, M.; Hall, M.A.; et al. Aurora kinases A and B are up-regulated by Myc and are essential for maintenance of the malignant state. Blood 2010, 116, 1498-1505. [CrossRef] [PubMed]

45. Bogen, D.; Wei, J.S.; Azorsa, D.O.; Ormanoglu, P.; Guha, R.; Keller, J.M.; Griner, L.A.M.; Song, Y.K.; Liao, H.; Mendoza, A.; et al. Aurora B kinase is a potent and selective target in MYCN-driven neuroblastoma. Oncotarget 2015, 6, 35247-35262. [CrossRef] [PubMed]

46. Jiang, J.; Wang, J.; Yue, M.; Cai, X.; Wang, T.; Wu, C.; Su, H.; Wang, Y.; Han, M.; Zhang, Y.; et al. Direct Phosphorylation and Stabilization of MYC by Aurora B Kinase Promote T-cell Leukemogenesis. Cancer Cell 2020, 37, 200-215.e5. [CrossRef] [PubMed]

47. Sradhanjali, S.; Tripathy, D.; Rath, S.; Mittal, R.; Reddy, M.M. Overexpression of pyruvate dehydrogenase kinase 1 in retinoblastoma: A potential therapeutic opportunity for targeting vitreous seeds and hypoxic regions. PLoS ONE 2017, 12, e0177744. [CrossRef]

48. Sradhanjali, S.; Reddy, M.M. Inhibition of Pyruvate Dehydrogenase Kinase as a Therapeutic Strategy against Cancer. Curr. Top. Med. Chem. 2018, 18, 444-453. [CrossRef] [PubMed]

49. Yang, J.; Ikezoe, T.; Nishioka, C.; Udaka, K.; Yokoyama, A. Bcr-Abl activates AURKA and AURKB in chronic myeloid leukemia cells via AKT signaling. Int. J. Cancer 2014, 134, 1183-1194. [CrossRef] [PubMed]

50. Wang, Y.; Wang, Z.; Qi, Z.; Yin, S.; Zhang, N.; Liu, Y.; Liu, M.; Meng, J.; Zang, R.; Zhang, Z.; et al. The negative interplay between Aurora A/B and BRCA1/2 controls cancer cell growth and tumorigenesis via distinct regulation of cell cycle progression, cytokinesis, and tetraploidy. Mol. Cancer 2014, 13, 1-12. [CrossRef]

51. Volodko, N.; Gordon, M.; Salla, M.; Ghazaleh, H.A.; Baksh, S. RASSF tumor suppressor gene family: Biological functions and regulation. FEBS Lett. 2014, 588, 2671-2684. [CrossRef]

52. Recino, A.; Sherwood, V.; Flaxman, A.; Cooper, W.N.; Latif, F.; Ward, A.; Chalmers, A.D. Human RASSF7 regulates the microtubule cytoskeleton and is required for spindle formation, Aurora B activation and chromosomal congression during mitosis. Biochem. J. 2010, 430, 207-213. [CrossRef] [PubMed]

53. Akhoondi, S.; Sun, D.; Von Der Lehr, N.; Apostolidou, S.; Klotz, K.; Maljukova, A.; Cepeda, D.; Fiegl, H.; Dofou, D.; Marth, C.; et al. FBXW7/hCDC4 is a general tumor suppressor in human cancer. Cancer Res. 2007, 67, 9006-9012. [CrossRef] [PubMed]

54. Sailo, B.L.; Banik, K.; Girisa, S.; Bordoloi, D.; Fan, L.; Halim, C.E.; Wang, H.; Kumar, A.P.; Zheng, D.; Mao, X.; et al. FBXW7 in cancer: What has been unraveled thus far? Cancers 2019, 11, 246. [CrossRef]

55. Li, Z.; Sun, Y.; Chen, X.; Squires, J.; Nowroozizadeh, B.; Liang, C.; Huang, J. P53 mutation directs AURKA overexpression via miR-25 and FBXW7 in prostatic small cell neuroendocrine carcinoma. Mol. Cancer Res. 2015, 13, 584-591. [CrossRef]

56. Teng, C.L.; Hsieh, Y.C.; Phan, L.; Shin, J.; Gully, C.; Velazquez-Torres, G.; Skerl, S.; Yeung, S.C.J.; Hsu, S.L.; Lee, M.H. FBXW7 is involved in Aurora B degradation. Cell Cycle 2012, 11, 4059-4068. [CrossRef] 
57. Gully, C.P.; Velazquez-Torres, G.; Shin, J.H.; Fuentes-Mattei, E.; Wang, E.; Carlock, C.; Chen, J.; Rothenberg, D.; Adams, H.P.; Choi, H.H.; et al. Aurora B kinase phosphorylates and instigates degradation of p53. Proc. Natl. Acad. Sci. USA 2012, 109, 1513-1522. [CrossRef]

58. Wu, L.; Ma, C.A.; Zhao, Y.; Jain, A. Aurora B interacts with NIR-p53, leading to p53 phosphorylation in its DNA-binding domain and subsequent functional suppression. J. Biol. Chem. 2011, 286, 2236-2244. [CrossRef]

59. Jha, H.C.; Yang, K.; El-Naccache, D.W.; Sun, Z.; Robertson, E.S. EBNA3C regulates p53 through induction of Aurora kinase B. Oncotarget 2015, 6, 5788-5803. [CrossRef]

60. Kanagasabai, T.; Venkatesan, T.; Natarajan, U.; Alobid, S.; Alhazzani, K.; Algahtani, M.; Rathinavelu, A. Regulation of cell cycle by MDM2 in prostate cancer cells through Aurora Kinase-B and p21WAF1(/CIP1) mediated pathways. Cell. Signal. 2020, 66, 109435. [CrossRef] [PubMed]

61. Schecher, S.; Walter, B.; Falkenstein, M.; Macher-Goeppinger, S.; Stenzel, P.; Krümpelmann, K.; Hadaschik, B.; Perner, S.; Kristiansen, G.; Duensing, S.; et al. Cyclin K dependent regulation of Aurora B affects apoptosis and proliferation by induction of mitotic catastrophe in prostate cancer. Int. J. Cancer 2017, 141, 1643-1653. [CrossRef] [PubMed]

62. Groot, C.O.D.; Hsia, J.E.; Anzola, J.V.; Motamedi, A. A Cell Biologist's Field Guide to Aurora Kinase Inhibitors. Front. Oncol. 2015, 5, 285. [CrossRef]

63. Hauf, S.; Cole, R.W.; LaTerra, S.; Zimmer, C.; Schnapp, G.; Walter, R.; Heckel, A.; Van Meel, J.; Rieder, C.L.; Peters, J.M. The small molecule Hesperadin reveals a role for Aurora B in correcting kinetochore-microtubule attachment and in maintaining the spindle assembly checkpoint. J. Cell Biol. 2003, 161, 281-294. [CrossRef] [PubMed]

64. Sessa, F.; Mapelli, M.; Ciferri, C.; Tarricone, C.; Areces, L.B.; Schneider, T.R.; Stukenberg, P.T.; Musacchio, A. Mechanism of Aurora B activation by INCENP and inhibition by hesperadin. Mol. Cell 2005, 18, 379-391. [CrossRef] [PubMed]

65. Shamsipour, F.; Hosseinzadeh, S.; Arab, S.S.; Vafaei, S.; Farid, S.; Jeddi-Tehrani, M.; Balalaie, S. Synthesis and investigation of new Hesperadin analogues antitumor effects on HeLa cells. J. Chem. Biol. 2014, 7, 85-91. [CrossRef]

66. Yang, J.; Ikezoe, T.; Nishioka, C.; Tasaka, T.; Taniguchi, A.; Kuwayama, Y.; Komatsu, N.; Bandobashi, K.; Togitani, K.; Koeffler, H.P.; et al. AZD1152, a novel and selective aurora B kinase inhibitor, induces growth arrest, apoptosis, and sensitization for tubulin depolymerizing agent or topoisomerase II inhibitor in human acute leukemia cells in vitro and in vivo. Blood 2007, 110, 2034-2040. [CrossRef]

67. Bertran-Alamillo, J.; Cattan, V.; Schoumacher, M.; Codony-Servat, J.; Giménez-Capitán, A.; Cantero, F.; Burbridge, M.; Rodríguez, S.; Teixidó, C.; Roman, R.; et al. AURKB as a target in non-small cell lung cancer with acquired resistance to anti-EGFR therapy. Nat. Commun. 2019, 10, 1-14. [CrossRef]

68. Helfrich, B.A.; Kim, J.; Gao, D.; Chan, D.C.; Zhang, Z.; Tan, A.P.A.B., Jr. Barasertib (AZD1152), a Small Molecule Aurora B Inhibitor, Inhibits the Growth of SCLC Cell Lines In Vitro and In Vivo. Mol. Cancer Ther. 2016, 15, 2314-2323. [CrossRef] [PubMed]

69. Wilkinson, R.W.; Odedra, R.; Heaton, S.P.; Wedge, S.R.; Keen, N.J.; Crafter, C.; Foster, J.R.; Brady, M.C.; Bigley, A.; Brown, E.; et al. AZD1152, a selective inhibitor of Aurora B kinase, inhibits human tumor xenograft growth by inducing apoptosis. Clin. Cancer Res. 2007, 13, 3682-3688. [CrossRef] [PubMed]

70. Tsuboi, K.; Yokozawa, T.; Sakura, T.; Watanabe, T.; Fujisawa, S.; Yamauchi, T.; Uike, N.; Ando, K.; Kihara, R.; Tobinai, K.; et al. A phase I study to assess the safety, pharmacokinetics and efficacy of barasertib (AZD1152), an Aurora B kinase inhibitor, in Japanese patients with advanced acute myeloid leukemia. Leuk. Res. 2011, 35, 1384-1389. [CrossRef]

71. Dennis, M.; Davies, M.; Oliver, S.; D'Souza, R.; Pike, L.; Stockman, P. Phase i study of the Aurora B kinase inhibitor barasertib (AZD1152) to assess the pharmacokinetics, metabolism and excretion in patients with acute myeloid leukemia. Cancer Chemother. Pharmacol. 2012, 70, 461-469. [CrossRef] [PubMed]

72. Creutzig, U.; Kaspers, G.J.L. Revised recommendations of the International Working Group for diagnosis, standardization of response criteria, treatment outcomes, and reporting standards for therapeutic trials in acute myeloid leukemia. J. Clin. Oncol. 2004, 22, 3432-3433. [CrossRef]

73. Kantarjian, H.M.; Martinelli, G.; Jabbour, E.J.; Quintás-Cardama, A.; Ando, K.; Bay, J.O.; Wei, A.; Gröpper, S.; Papayannidis, C.; Owen, K.; et al. Stage i of a phase 2 study assessing the efficacy, safety, and tolerability of barasertib (AZD1152) versus low-dose cytosine arabinoside in elderly patients with acute myeloid leukemia. Cancer 2013, 119, 2611-2619. [CrossRef] [PubMed]

74. Kantarjian, H.M.; Sekeres, M.A.; Ribrag, V.; Rousselot, P.; Garcia-Manero, G.; Jabbour, E.J.; Owen, K.; Stockman, P.K.; Oliver, S.D. Phase i study assessing the safety and tolerability of barasertib (azd1152) with low-dose cytosine arabinoside in elderly patients with AML. Clin. Lymphoma Myeloma Leuk. 2013, 13, 559-567. [CrossRef]

75. Boss, D.S.; Witteveen, P.O.; Van der Sar, J.; Lolkema, M.P.; Voest, E.E.; Stockman, P.K.; Ataman, O.; Wilson, D.; Das, S.; Schellens, J.H. Clinical evaluation of AZD1152, an i.v. inhibitor of Aurora B kinase, in patients with solid malignant tumors. Ann. Oncol. 2011, 22, 431-437. [CrossRef]

76. Schwartz, G.K.; Carvajal, R.D.; Midgley, R.; Rodig, S.J.; Stockman, P.K.; Ataman, O.; Wilson, D.; Das, S.; Shapiro, G.I. Phase i study of barasertib (AZD1152), a selective inhibitor of Aurora B kinase, in patients with advanced solid tumors. Investig. New Drugs 2013, 31, 370-380. [CrossRef]

77. Collins, G.P.; Eyre, T.A.; Linton, K.M.; Radford, J.; Vallance, G.D.; Soilleux, E.; Hatton, C. A phase II trial of AZD1152 in relapsed/refractory diffuse large B-cell lymphoma. Br. J. Haematol. 2015, 170, 886-890. [CrossRef] [PubMed]

78. Lakkaniga, N.R.; Zhang, L.; Belachew, B.; Gunaganti, N.; Frett, B.; Li, H. yu Discovery of SP-96, the first non-ATP-competitive Aurora Kinase B inhibitor, for reduced myelosuppression. Eur. J. Med. Chem. 2020, 203, 112589. [CrossRef] 
79. Davis, M.I.; Hunt, J.P.; Herrgard, S.; Ciceri, P.; Wodicka, L.M.; Pallares, G.; Hocker, M.; Treiber, D.K.; Zarrinkar, P.P. Comprehensive analysis of kinase inhibitor selectivity. Nat. Biotechnol. 2011, 29, 1046-1051. [CrossRef]

80. Floc'H, N.; Ashton, S.; Taylor, P.; Trueman, D.; Harris, E.; Odedra, R.; Maratea, K.; Derbyshire, N.; Caddy, J.; Jacobs, V.N.; et al. Optimizing Therapeutic Effect of Aurora B Inhibition in Acute Myeloid Leukemia with AZD2811 Nanoparticles. Mol. Cancer Ther. 2017, 16, 1031-1040. [CrossRef] [PubMed]

81. Floc'h, N.; Ashton, S.; Ferguson, D.; Taylor, P.; Carnevalli, L.S.; Hughes, A.M.; Harris, E.; Hattersley, M.; Wen, S.; Curtis, N.J.; et al Modeling dose and schedule effects of AZD2811 nanoparticles targeting aurora $b$ kinase for treatment of diffuse large b-cell lymphoma. Mol. Cancer Ther. 2019, 18, 909-919. [CrossRef] [PubMed]

82. Zekri, A.; Ghaffari, S.H.; Ghanizadeh-Vesali, S.; Yaghmaie, M.; Salmaninejad, A.; Alimoghaddam, K.; Modarressi, M.H.; Ghavamzadeh, A. AZD1152-HQPA induces growth arrest and apoptosis in androgen-dependent prostate cancer cell line (LNCaP) via producing aneugenic micronuclei and polyploidy. Tumor Biol. 2015, 36, 623-632. [CrossRef] [PubMed]

83. He, J.; Qi, Z.; Zhang, X.; Yang, Y.; Liu, F.; Zhao, G.; Wang, Z. Aurora kinase B inhibitor barasertib (AZD1152) inhibits glucose metabolism in gastric cancer cells. Anticancer. Drugs 2019, 30, 19-26. [CrossRef]

84. Aihara, A.; Tanaka, S.; Yasen, M.; Matsumura, S.; Mitsunori, Y.; Murakata, A.; Noguchi, N.; Kudo, A.; Nakamura, N.; Ito, K.; et al. The selective Aurora B kinase inhibitor AZD1152 as a novel treatment for hepatocellular carcinoma. J. Hepatol. 2010, 52, 63-71. [CrossRef]

85. Noronha, S.; Alt, L.A.C.; Scimeca, T.E.; Zarou, O.; Obrzut, J.; Zanotti, B.; Hayward, E.A.; Pillai, A.; Mathur, S.; Rojas, J.; et al. Preclinical evaluation of the Aurora kinase inhibitors AMG 900, AZD1152-HQPA, and MK-5108 on SW-872 and 93 T449 human liposarcoma cells. Vitr. Cell. Dev. Biol. Anim. 2018, 54, 71-84. [CrossRef]

86. Tao, Y.; Zhang, P.; Girdler, F.; Frascogna, V.; Castedo, M.; Bourhis, J.; Kroemer, G.; Deutsch, E. Enhancement of radiation response in p53-deficient cancer cells by the Aurora-B kinase inhibitor AZD1152. Oncogene 2008, 27, 3244-3255. [CrossRef] [PubMed]

87. Gully, C.P.; Zhang, F.; Chen, J.; Yeung, J.A.; Velazquez-Torres, G.; Wang, E.; Yeung, S.C.J.; Lee, M.H. Antineoplastic effects of an Aurora B kinase inhibitor in breast cancer. Mol. Cancer 2010, 9, 1-13. [CrossRef]

88. Baldini, E.; Tuccilli, C.; Prinzi, N.; Sorrenti, S.; Antonelli, A.; Gnessi, L.; Morrone, S.; Moretti, C.; Bononi, M.; Arlot-Bonnemains, Y.; et al. Effects of selective inhibitors of Aurora kinases on anaplastic thyroid carcinoma cell lines. Endocr. Relat. Cancer 2014, $21,797-811$. [CrossRef]

89. Sánchez-Molina, S.; Figuerola-Bou, E.; Blanco, E.; Sánchez-Jiménez, M.; Táboas, P.; Gómez, S.; Ballaré, C.; García-Domínguez, D.J.; Prada, E.; Hontecillas-Prieto, L.; et al. RING1B recruits EWSR1-FLI1 and cooperates in the remodeling of chromatin necessary for Ewing sarcoma tumorigenesis. Sci. Adv. 2020, 6. [CrossRef]

90. Tuccilli, C.; Baldini, E.; Prinzi, N.; Morrone, S.; Sorrenti, S.; Filippini, A.; Catania, A.; Alessandrini, S.; Rendina, R.; Coccaro, C.; et al. Preclinical testing of selective Aurora kinase inhibitors on a medullary thyroid carcinoma-derived cell line. Endocrine 2016, 52, 287-295. [CrossRef]

91. Zhu, X.P.; Liu, Z.L.; Peng, A.F.; Zhou, Y.F.; Long, X.H.; Luo, Q.F.; Huang, S.H.; Shu, Y. Inhibition of Aurora-B suppresses osteosarcoma cell migration and invasion. Exp. Ther. Med. 2014, 7, 560-564. [CrossRef]

92. Löwenberg, B.; Muus, P.; Ossenkoppele, G.; Rousselot, P.; Cahn, J.Y.; Ifrah, N.; Martinelli, G.; Amadori, S.; Berman, E.; Sonneveld, P.; et al. Phase 1/2 study to assess the safety, efficacy, and pharmacokinetics of barasertib (AZD1152) in patients with advanced acute myeloid leukemia. Blood 2011, 118, 6030-6036. [CrossRef]

93. Quintás-Cardama, A.; Ravandi, F.; Liu-Dumlao, T.; Brandt, M.; Faderl, S.; Pierce, S.; Borthakur, G.; Garcia-Manero, G.; Cortes, J.; Kantarjian, H. Epigenetic therapy is associated with similar survival compared with intensive chemotherapy in older patients with newly diagnosed acute myeloid leukemia. Blood 2012, 120, 4840-4845. [CrossRef]

94. McNeish, I.; Anthoney, A.; Loadman, P.; Berney, D.; Joel, S.; Halford, S.E.R.; Buxton, E.; Race, A.; Ikram, M.; Scarsbrook, A.; et al. A phase I pharmacokinetic (PK) and pharmacodynamic (PD) study of the selective aurora kinase inhibitor GSK1070916A. J. Clin. Oncol. 2013, 31, 2525. [CrossRef]

95. Dent, S.F.; Gelmon, K.A.; Chi, K.N.; Jonker, D.J.; Wainman, N.; Capier, C.A.; Chen, E.X.; Lyons, J.F.; Seymour, L. NCIC CTG IND.181: Phase i study of AT9283 given as a weekly $24 \mathrm{~h}$ infusion in advanced malignancies. Investig. New Drugs 2013, 31, 1522-1529. [CrossRef] [PubMed]

96. Hay, A.E.; Murugesan, A.; Dipasquale, A.M.; Kouroukis, T.; Sandhu, I.; Kukreti, V.; Bahlis, N.J.; Lategan, J.; Reece, D.E.; Lyons, J.F; et al. A phase II study of AT9283, an aurora kinase inhibitor, in patients with relapsed or refractory multiple myeloma: NCIC clinical trials group IND.191. Leuk. Lymphoma 2016, 57, 1463-1466. [CrossRef]

97. Foran, J.; Ravandi, F.; Wierda, W.; Garcia-Manero, G.; Verstovsek, S.; Kadia, T.; Burger, J.; Yule, M.; Langford, G.; Lyons, J.; et al. A phase i and pharmacodynamic study of AT9283, a small-molecule inhibitor of aurora kinases in patients with relapsed/refractory leukemia or myelofibrosis. Clin. Lymphoma, Myeloma Leuk. 2014, 14, 223-230. [CrossRef] [PubMed]

98. Vormoor, B.; Veal, G.J.; Griffin, M.J.; Boddy, A.V.; Irving, J.; Minto, L.; Case, M.; Banerji, U.; Swales, K.E.; Tall, J.R.; et al. A phase I/II trial of AT9283, a selective inhibitor of aurora kinase in children with relapsed or refractory acute leukemia: Challenges to run early phase clinical trials for children with leukemia. Pediatr. Blood Cancer 2017, 64, 1-4. [CrossRef]

99. Arkenau, H.T.; Plummer, R.; Molife, L.R.; Olmos, D.; Yap, T.A.; Squires, M.; Lewis, S.; Lock, V.; Yule, M.; Lyons, J.; et al. A phase I dose escalation study of AT9283, a small molecule inhibitor of aurora kinases, in patients with advanced solid malignancies. Ann. Oncol. 2012, 23, 1307-1313. [CrossRef] 
100. Moreno, L.; Marshall, L.V.; Pearson, A.D.J.; Morland, B.; Elliott, M.; Campbell-Hewson, Q.; Makin, G.; Halford, S.E.R.; Acton, G.; Ross, P.; et al. A phase i trial of AT9283 (a selective inhibitor of aurora kinases) in children and adolescents with solid tumors: A cancer research UK study. Clin. Cancer Res. 2015, 21, 267-273. [CrossRef] [PubMed]

101. Duong, J.K.; Griffin, M.J.; Hargrave, D.; Vormoor, J.; Edwards, D.; Boddy, A. V A population pharmacokinetic model of AT9283 in adults and children to predict the maximum tolerated dose in children with leukaemia. Br. J. Clin. Pharmacol. 2017, 83, 1713-1722. [CrossRef]

102. Cohen, R.B.; Jones, S.F.; Aggarwal, C.; Von Mehren, M.; Cheng, J.; Spigel, D.R.; Greco, F.A.; Mariani, M.; Rocchetti, M.; Ceruti, R.; et al. A phase I dose-escalation study of danusertib (PHA-739358) administered as a 24-h infusion with and without granulocyte colony-stimulating factor in a 14-day cycle in patients with advanced solid tumors. Clin. Cancer Res. 2009, 15, 6694-6701. [CrossRef] [PubMed]

103. Borthakur, G.; Dombret, H.; Schafhausen, P.; Brummendorf, T.H.; Boisse, N.; Jabbour, E.; Mariani, M.; Capolongo, L.; Carpinelli, P.; Davite, C.; et al. A phase I study of danusertib (PHA-739358) in adult patients with accelerated or blastic phase chronic myeloid leukemia and philadelphia chromosome-positive acute lymphoblastic leukemia resistant or intolerant to imatinib and/or other second generation c-ABL therapy. Haematologica 2015, 100, 898-904. [CrossRef]

104. Meulenbeld, H.J.; Bleuse, J.P.; Vinci, E.M.; Raymond, E.; Vitali, G.; Santoro, A.; Dogliotti, L.; Berardi, R.; Cappuzzo, F.; Tagawa, S.T.; et al. Randomized phase II study of danusertib in patients with metastatic castration-resistant prostate cancer after docetaxel failure. BJU Int. 2013, 111, 44-52. [CrossRef]

105. Steeghs, N.; Eskens, F.A.L.M.; Gelderblom, H.; Verweij, J.; Nortier, J.W.R.; Ouwerkerk, J.; Van Noort, C.; Mariani, M.; Spinelli, R.; Carpinelli, P.; et al. Phase I pharmacokinetic and pharmacodynamic study of the aurora kinase inhibitor danusertib in patients with advanced or metastatic solid tumors. J. Clin. Oncol. 2009, 27, 5094-5101. [CrossRef]

106. Kantarjian, H.M.; Schuster, M.W.; Jain, N.; Advani, A.; Jabbour, E.; Gamelin, E.; Rasmussen, E.; Juan, G.; Anderson, A.; Chow, V.F.; et al. A phase 1 study of AMG 900, an orally administered pan-aurora kinase inhibitor, in adult patients with acute myeloid leukemia. Am. J. Hematol. 2017, 92, 660-667. [CrossRef]

107. Carducci, M.; Shaheen, M.; Markman, B.; Hurvitz, S.; Mahadevan, D.; Kotasek, D.; Goodman, O.B.; Rasmussen, E.; Chow, V.; Juan, G.; et al. A phase 1, first-in-human study of AMG 900, an orally administered pan-Aurora kinase inhibitor, in adult patients with advanced solid tumors. Investig. New Drugs 2018, 36, 1060-1071. [CrossRef] [PubMed]

108. Mross, K.; Richly, H.; Frost, A.; Scharr, D.; Nokay, B.; Graeser, R.; Lee, C.; Hilbert, J.; Goeldner, R.G.; Fietz, O.; et al. A phase I study of BI 811283, an Aurora B kinase inhibitor, in patients with advanced solid tumors. Cancer Chemother. Pharmacol. 2016, 78, 405-417. [CrossRef]

109. Döhner, H.; Müller-Tidow, C.; Lübbert, M.; Fiedler, W.; Krämer, A.; Westermann, J.; Bug, G.; Schlenk, R.F.; Krug, U.; Goeldner, R.G.; et al. A phase I trial investigating the Aurora B kinase inhibitor BI 811283 in combination with cytarabine in patients with acute myeloid leukaemia. Br. J. Haematol. 2019, 185, 583-587. [CrossRef] [PubMed]

110. Johnson, M.L.; Cosaert, J.G.C.E.; Falchook, G.S.; Jones, S.F.; Strickland, D.; Greenlees, C.; Charlton, J.; MacDonald, A.; Overend, P.; Adelman, C.; et al. A phase I, open label, multicenter dose escalation study of AZD2811 nanoparticle in patients with advanced solid tumors. J. Clin. Oncol. 2019, 37, 3098. [CrossRef]

111. Park, S.; Shim, J.; Jung, H.A.; Sun, J.-M.; Lee, S.-H.; Park, W.-Y.; Ahn, J.S.; Ahn, M.-J.; Park, K. Biomarker driven phase II umbrella trial study of AZD1775, AZD2014, AZD2811 monotherapy in relapsed small cell lung cancer. J. Clin. Oncol. 2019, $37,8514$. [CrossRef]

112. Donnellan, W.B.; Atallah, E.L.; Asch, A.S.; Patel, M.R.; Yang, J.; Eghtedar, A.; Borthakur, G.M.; Charlton, J.; MacDonald, A.; Korzeniowska, A.; et al. A Phase I/II Study of AZD2811 Nanoparticles (NP) As Monotherapy or in Combination in TreatmentNaïve or Relapsed/Refractory AML/MDS Patients Not Eligible for Intensive Induction Therapy. Blood 2019, 134, 3919. [CrossRef]

113. Adams, N.D.; Adams, J.L.; Burgess, J.L.; Chaudhari, A.M.; Copeland, R.A.; Donatelli, C.A.; Drewry, D.H.; Fisher, K.E.; Hamajima, T.; Hardwicke, M.A.; et al. Discovery of GSK1070916, a potent and selective inhibitor of aurora B/C kinase. J. Med. Chem. 2010, 53, 3973-4001. [CrossRef]

114. Hardwicke, M.A.; Oleykowski, C.A.; Plant, R.; Wang, J.; Liao, Q.; Moss, K.; Newlander, K.; Adams, J.L.; Dhanak, D.; Yang, J.; et al. GSK 1070916, a potent Aurora B/C kinase inhibitor with broad antitumor activity in tissue culture cells and human tumor xenograft models. Mol. Cancer Ther. 2009, 8, 1808-1817. [CrossRef]

115. Spartà, A.M.; Bressanin, D.; Chiarini, F.; Lonetti, A.; Cappellini, A.; Evangelisti, C.; Evangelisti, C.; Melchionda, F.; Pession, A.; Bertaina, A.; et al. Therapeutic targeting of Polo-like kinase-1 and Aurora kinases in T-cell acute lymphoblastic leukemia. Cell Cycle 2014, 13, 2237-2247. [CrossRef] [PubMed]

116. Wu, Z.-X.; Yang, Y.; Wang, J.-Q.; Zhou, W.-M.; Chen, J.; Fu, Y.-G.; Patel, K.; Chen, Z.-S.; Zhang, J.-Y. Elevated ABCB1 Expression Confers Acquired Resistance to Aurora Kinase Inhibitor GSK-1070916 in Cancer Cells. Front. Pharmacol. 2020, $11,615824$. [CrossRef] [PubMed]

117. Zi, D.; Zhou, Z.W.; Yang, Y.J.; Huang, L.; Zhou, Z.L.; He, S.M.; He, Z.X.; Zhou, S.F. Danusertib induces apoptosis, cell cycle arrest, and autophagy but inhibits epithelial to mesenchymal transition involving PI3K/Akt/mTOR signaling pathway in human ovarian cancer cells. Int. J. Mol. Sci. 2015, 16, 27228-27251. [CrossRef] [PubMed]

118. Fraedrich, K.; Schrader, J.; Ittrich, H.; Keller, G.; Gontarewicz, A.; Matzat, V.; Kromminga, A.; Pace, A.; Moll, J.; Bläker, M.; et al. TarGeting aurora kinases with danusertib (PHA-739358) inhibits growth of liver metastases from gastroenteropancreatic neuroendocrine tumors in an orthotopic xenograft model. Clin. Cancer Res. 2012, 18, 4621-4632. [CrossRef] [PubMed] 
119. Shang, Y.Y.; Yu, N.; Xia, L.; Yu, Y.Y.; Ma, C.M.; Jiao, Y.N.; Li, Y.F.; Wang, Y.; Dang, J.; Li, W. Augmentation of danusertib's anticancer activity against melanoma by blockage of autophagy. Drug Deliv. Transl. Res. 2020, 10, 136-145. [CrossRef] [PubMed]

120. Yuan, C.X.; Zhou, Z.W.; Yang, Y.X.; He, Z.X.; Zhang, X.; Wang, D.; Yang, T.; Pan, S.Y.; Chen, X.W.; Zhou, S.F. Danusertib, a potent pan-Aurora kinase and ABL kinase inhibitor, induces cell cycle arrest and programmed cell death and inhibits epithelial to mesenchymal transition involving the Pi3K/Akt/mTOR-mediated signaling pathway in human gastric cancer AGS and N. Drug Des. Devel. Ther. 2015, 9, 1293-1318. [CrossRef] [PubMed]

121. Zhu, Q.; Yu, X.; Zhou, Z.-W.; Luo, M.; Zhou, C.; He, Z.-X.; Chen, Y.; Zhou, S.-F. A quantitative proteomic response of hepatocellular carcinoma Hep3B cells to danusertib, a pan-Aurora kinase inhibitor. J. Cancer 2018, 9, 2061-2071. [CrossRef]

122. Balabanov, S.; Gontarewicz, A.; Keller, G.; Raddrizzani, L.; Braig, M.; Bosotti, R.; Moll, J.; Jost, E.; Barett, C.; Rohe, I.; et al. Abcg2 overexpression represents a novel mechanism for acquired resistance to the multi-kinase inhibitor danusertib in BCR-ABL-positive cells in vitro. PLoS ONE 2011, 6, e19164. [CrossRef]

123. Li, J.P.; Yang, Y.X.; Liu, Q.L.; Zhou, Z.W.; Pan, S.T.; He, Z.X.; Zhang, X.; Yang, T.; Pan, S.Y.; Duan, W.; et al. The pan-inhibitor of aurora kinases danusertib induces apoptosis and autophagy and suppresses epithelial-to-mesenchymal transition in human breast cancer cells. Drug Des. Devel. Ther. 2015, 9, 1027-1062. [CrossRef]

124. He, S.J.; Shu, L.P.; Zhou, Z.W.; Yang, T.; Duan, W.; Zhang, X.; He, Z.X.; Zhou, S.F. Inhibition of Aurora kinases induces apoptosis and autophagy via AURKB/p70S6K/RPL15 axis in human leukemia cells. Cancer Lett. 2016, 382, 215-230. [CrossRef]

125. Xie, L.; Meyskens, F.L. The pan-Aurora kinase inhibitor, PHA-739358, induces apoptosis and inhibits migration in melanoma cell lines. Melanoma Res. 2013, 23, 102-113. [CrossRef]

126. Zhang, Y.; Zhang, B.; Feng, W.; Li, Y.; Cao, X. Molecular mechanism of Aurora kinase inhibitor PHA739358 in inhibited proliferation and induced apoptosis of breast cancer cells. Zhonghua Yi Xue Za Zhi 2012, 92, 45-49.

127. Benten, D.; Keller, G.; Quaas, A.; Schrader, J.; Gontarewicz, A.; Balabanov, S.; Braig, M.; Wege, H.; Moll, J.; Lohse, A.W.; et al. Aurora kinase inhibitor PHA-739358 suppresses growth of hepatocellular carcinoma in vitro and in a xenograft mouse model. Neoplasia 2009, 11, 934-944. [CrossRef]

128. Fei, F.; Lim, M.; Schmidhuber, S.; Moll, J.; Groffen, J.; Heisterkamp, N. Treatment of human pre-B acute lymphoblastic leukemia with the Aurora kinase inhibitor PHA-739358 (Danusertib). Mol. Cancer 2012, 11, 1-12. [CrossRef] [PubMed]

129. Howard, S.; Berdini, V.; Boulstridge, J.A.; Carr, M.G.; Cross, D.M.; Curry, J.; Devine, L.A.; Early, T.R.; Fazal, L.; Gill, A.L.; et al. Fragment-based discovery of the pyrazol-4-yl urea (AT9283), a multitargeted kinase inhibitor with potent aurora kinase activity. J. Med. Chem. 2009, 52, 379-388. [CrossRef] [PubMed]

130. Qi, W.; Liu, X.; Cooke, L.S.; Persky, D.O.; Miller, T.P.; Squires, M.; Mahadevan, D. AT9283, a novel aurora kinase inhibitor, suppresses tumor growth in aggressive B-cell lymphomas. Int. J. Cancer 2012, 130, 2997-3005. [CrossRef]

131. Mills, C.C.; Kolb, E.A.; Sampson, V.B. Recent advances of cell-cycle inhibitor therapies for pediatric cancer. Cancer Res. 2017, 77, 6489-6498. [CrossRef] [PubMed]

132. Takeda, T.; Tsubaki, M.; Genno, S.; Nemoto, C.; Onishi, Y.; Yamamoto, Y.; Imano, M.; Satou, T.; Nishida, S. AT9283 exhibits antiproliferative effect on tyrosine kinase inhibitor-sensitive and -resistant chronic myeloid leukemia cells by inhibition of Aurora A and Aurora B. Oncol. Rep. 2020, 44, 2211-2218. [CrossRef] [PubMed]

133. Tanaka, R.; Squires, M.S.; Kimura, S.; Yokota, A.; Nagao, R.; Yamauchi, T.; Takeuchi, M.; Yao, H.; Reule, M.; Smyth, T.; et al. Activity of the multitargeted kinase inhibitor, AT9283, in imatinib-resistant BCR-ABL-positive leukemic cells. Blood 2010, 116, 2089-2095. [CrossRef] [PubMed]

134. Geuns-Meyer, S.; Cee, V.J.; Deak, H.L.; Du, B.; Hodous, B.L.; Nguyen, H.N.; Olivieri, P.R.; Schenkel, L.B.; Vaida, K.R.; Andrews, P.; et al. Discovery of N -(4-(3-(2-Aminopyrimidin-4-yl)pyridin-2-yloxy)phenyl)-4-(4-methylthiophen-2-yl)phthalazin-1-amine (AMG 900), A Highly Selective, Orally Bioavailable Inhibitor of Aurora Kinases with Activity against Multidrug-Resistant Cancer Cell Lines. J. Med. Chem. 2015, 58, 5189-5207. [CrossRef] [PubMed]

135. Ryu, J.; Pyo, J.; Lee, C.W.; Kim, J.E. An Aurora kinase inhibitor, AMG900, inhibits glioblastoma cell proliferation by disrupting mitotic progression. Cancer Med. 2018, 7, 5589-5603. [CrossRef] [PubMed]

136. Payton, M.; Cheung, H.-K.; Ninniri, M.S.S.; Marinaccio, C.; Wayne, W.C.; Hanestad, K.; Crispino, J.D.; Juan, G.; Coxon, A. Dual Targeting of Aurora Kinases with AMG 900 Exhibits Potent Preclinical Activity Against Acute Myeloid Leukemia with Distinct Post-Mitotic Outcomes. Mol. Cancer Ther. 2018, 17, 2575-2585. [CrossRef]

137. Kalous, O.; Conklin, D.; Desai, A.J.; Dering, J.; Goldstein, J.; Ginther, C.; Anderson, L.; Lu, M.; Kolarova, T.; Eckardt, M.A.; et al. AMG 900, pan-Aurora kinase inhibitor, preferentially inhibits the proliferation of breast cancer cell lines with dysfunctional p53. Breast Cancer Res. Treat. 2013, 141, 397-408. [CrossRef]

138. Wang, S.; Midgley, C.A.; Scaërou, F.; Grabarek, J.B.; Griffiths, G.; Jackson, W.; Kontopidis, G.; McClue, S.J.; McInnes, C.; Meades, C.; et al. Discovery of N-Phenyl-4-(thiazol-5-yl)pyrimidin-2-amine aurora kinase inhibitors. J. Med. Chem. 2010, 53, 4367-4378. [CrossRef] [PubMed]

139. Soncini, C.; Carpinelli, P.; Gianellini, L.; Fancelli, D.; Vianello, P.; Rusconi, L.; Storici, P.; Zugnoni, P.; Pesenti, E.; Croci, V.; et al. PHA-680632, a novel aurora kinase inhibitor with potent antitumoral activity. Clin. Cancer Res. 2006, 12, 4080-4089. [CrossRef]

140. Lima, K.; Carlos, J.A.E.G.; de Melo Alves-Paiva, R.; Vicari, H.P.; de Souza Santos, F.P.; Hamerschlak, N.; Costa-Lotufo, L.V.; Traina, F.; Machado-Neto, J.A. Reversine exhibits antineoplastic activity in JAK2V617F-positive myeloproliferative neoplasms. Sci. Rep. 2019, 9, 1-9. [CrossRef] 
141. Cheng, C.; Liu, Z.G.; Zhang, H.; Xie, J.D.; Chen, X.G.; Zhao, X.Q.; Wang, F.; Liang, Y.J.; Chen, L.K.; Singh, S.; et al. Enhancing chemosensitivity in ABCB1- and ABCG2-overexpressing cells and cancer stem-like cells by an Aurora kinase inhibitor CCT129202. Mol. Pharm. 2012, 9, 1971-1982. [CrossRef]

142. Okcanoğlu, T.B.; Kayabaşı, Ç.; Gündüz, C. Effect of CCT137690 on long non-coding RNA expression profiles in MCF-7 and MDA-MB-231 cell lines. Bosn. J. Basic Med. Sci. 2020, 20, 56-62. [CrossRef]

143. Furqan, M.; Huma, Z.; Ashfaq, Z.; Nasir, A.; Ullah, R.; Bilal, A.; Iqbal, M.; Khalid, M.H.; Hussain, I.; Faisal, A. Identification and evaluation of novel drug combinations of Aurora kinase inhibitor CCT137690 for enhanced efficacy in oral cancer cells. Cell Cycle 2019, 18, 2281-2292. [CrossRef]

144. Arbitrario, J.P.; Belmont, B.J.; Evanchik, M.J.; Flanagan, W.M.; Fucini, R.V.; Hansen, S.K.; Harris, S.O.; Hashash, A.; Hoch, U.; Hogan, J.N.; et al. SNS-314, a pan-Aurora kinase inhibitor, shows potent anti-tumor activity and dosing flexibility in vivo. Cancer Chemother. Pharmacol. 2010, 65, 707-717. [CrossRef] [PubMed]

145. Almatroodi, S.A.; Alsahli, M.A.; Almatroudi, A.; Verma, A.K.; Aloliqi, A.; Allemailem, K.S.; Khan, A.A.; Rahmani, A.H. Potential Therapeutic Targets of Quercetin, a Plant Flavonol, and Its Role in the Therapy of Various Types of Cancer through the Modulation of Various Cell Signaling Pathways. Molecules 2021, 26, 1315. [CrossRef]

146. Xingyu, Z.; Peijie, M.; Dan, P.; Youg, W.; Daojun, W.; Xinzheng, C.; Xijun, Z.; Yangrong, S. Quercetin suppresses lung cancer growth by targeting Aurora B kinase. Cancer Med. 2016, 5, 3156-3165. [CrossRef]

147. Huang, M.; Feng, X.; Su, D.; Wang, G.; Wang, C.; Tang, M.; Paulucci-Holthauzen, A.; Hart, T.; Chen, J. Genome-wide CRISPR screen uncovers a synergistic effect of combining Haspin and Aurora kinase B inhibition. Oncogene 2020. [CrossRef]

148. Traynor, A.M.; Hewitt, M.; Liu, G.; Flaherty, K.T.; Clark, J.; Freedman, S.J.; Scott, B.B.; Leighton, A.M.; Watson, P.A.; Zhao, B.; et al. Phase I dose escalation study of MK-0457, a novel Aurora kinase inhibitor, in adult patients with advanced solid tumors. Cancer Chemother. Pharmacol. 2011, 67, 305-314. [CrossRef]

149. Li, N.; Maly, D.J.; Chanthery, Y.H.; Sirkis, D.W.; Nakamura, J.L.; Berger, M.S.; James, C.D.; Shokat, K.M.; Weiss, W.A.; Persson, A.I. Radiotherapy followed by aurora kinase inhibition targets tumor-propagating cells in human glioblastoma. Mol. Cancer Ther. 2015, 14, 419-428. [CrossRef]

150. Pinel, S.; Barbault-Foucher, S.; Lott-Desroches, M.-C.; Astier, A. Inhibitors of aurora kinases. Ann. Pharm. Fr. 2009, 67, 69-77. [CrossRef] [PubMed]

151. Ding, Y.H.; Zhou, Z.W.; Ha, C.F.; Zhang, X.Y.; Pan, S.T.; He, Z.X.; Edelman, J.L.; Wang, D.; Yang, Y.X.; Zhang, X.; et al. Alisertib, an Aurora kinase A inhibitor, induces apoptosis and autophagy but inhibits epithelial to mesenchymal transition in human epithelial ovarian cancer cells. Drug Des. Devel. Ther. 2015, 9, 425-464. [CrossRef] [PubMed]

152. Yeung, S.-C.; Gully, C.; Lee, M.-H. Aurora-B Kinase Inhibitors for Cancer Chemotherapy. Mini-Reviews Med. Chem. 2008, 8 , 1514-1525. [CrossRef]

153. Santo, L.; Hideshima, T.; Cirstea, D.; Bandi, M.; Nelson, E.A.; Gorgun, G.; Rodig, S.; Vallet, S.; Pozzi, S.; Patel, K.; et al. Antimyeloma activity of a multitargeted kinase inhibitor, AT9283, via potent Aurora kinase and STAT3 inhibition either alone or in combination with lenalidomide. Clin. Cancer Res. 2011, 17, 3259-3271. [CrossRef] [PubMed]

154. Chang, X.; Zhang, T.; Wang, Q.; Rathore, M.G.; Reddy, K.; Chen, H.; Shin, S.H.; Ma, W.Y.; Bode, A.M.; Dong, Z. HI-511 overcomes melanoma drug resistance via targeting AURKB and BRAF V600E. Theranostics 2020, 10, 9721-9740. [CrossRef]

155. Azzariti, A.; Bocci, G.; Porcelli, L.; Fioravanti, A.; Sini, P.; Simone, G.M.; Quatrale, A.E.; Chiarappa, P.; Mangia, A.; Sebastian, S.; et al. Aurora B kinase inhibitor AZD1152: Determinants of action and ability to enhance chemotherapeutics effectiveness in pancreatic and colon cancer. Br. J. Cancer 2011, 104, 769-780. [CrossRef]

156. Boeckx, C.; Op de Beeck, K.; Wouters, A.; Deschoolmeester, V.; Limame, R.; Zwaenepoel, K.; Specenier, P.; Pauwels, P.; Vermorken, J.B.; Peeters, M.; et al. Overcoming cetuximab resistance in HNSCC: The role of AURKB and DUSP proteins. Cancer Lett. 2014, 354, 365-377. [CrossRef] [PubMed]

157. Hole, S.; Pedersen, A.M.; Lykkesfeldt, A.E.; Yde, C.W. Aurora kinase A and B as new treatment targets in aromatase inhibitorresistant breast cancer cells. Breast Cancer Res. Treat. 2015, 149, 715-726. [CrossRef] [PubMed]

158. Illert, A.L.; Seitz, A.K.; Rummelt, C.; Kreutmair, S.; Engh, R.A.; Goodstal, S.; Peschel, C.; Duyster, J.; von Bubnoff, N. Inhibition of Aurora kinase B is important for biologic activity of the dual inhibitors of BCR-ABL and Aurora kinases R763/AS703569 and PHA-739358 in BCR-ABL transformed cells. PLoS ONE 2014, 9, e112318. [CrossRef]

159. Failes, T.W.; Mitic, G.; Abdel-Halim, H.; Po'uha, S.T.; Liu, M.; Hibbs, D.E.; Kavallaris, M. Evolution of resistance to Aurora kinase B inhibitors in leukaemia cells. PLoS ONE 2012, 7, e30734. [CrossRef]

160. Guo, J.; Anderson, M.G.; Tapang, P.; Palma, J.P.; Rodriguez, L.E.; Niquette, A.; Li, J.; Bouska, J.J.; Wang, G.; Semizarov, D.; et al. Identification of genes that confer tumor cell resistance to the aurora B kinase inhibitor, AZD1152. Pharm. J. 2009, 9, 90-102. [CrossRef]

161. Girdler, F.; Sessa, F.; Patercoli, S.; Villa, F.; Musacchio, A.; Taylor, S. Molecular basis of drug resistance in aurora kinases. Chem. Biol. 2008, 15, 552-562. [CrossRef] [PubMed]

162. Lee, E.C.Y.; Frolov, A.; Li, R.; Ayala, G.; Greenberg, N.M. Targeting Aurora kinases for the treatment of prostate cancer. Cancer Res. 2006, 66, 4996-5002. [CrossRef]

163. Nair, J.S.; de Stanchina, E.; Schwartz, G.K. The topoisomerase I poison CPT-11 enhances the effect of the aurora B kinase inhibitor AZD1152 both in vitro and in vivo. Clin. Cancer Res. 2009, 15, 2022-2030. [CrossRef] 
164. Shah, O.J.; Lin, X.; Li, L.; Huang, X.; Li, J.; Anderson, M.G.; Tang, H.; Rodriguez, L.E.; Warder, S.E.; McLoughlin, S.; et al. Bcl-XL represents a druggable molecular vulnerability during aurora B inhibitor-mediated polyploidization. Proc. Natl. Acad. Sci. USA 2010, 107, 12634-12639. [CrossRef]

165. Guo, Y.; Wei, Q.; Tan, L.; Li, Y.; Li, J.; Li, L.; Jiang, T.; Zhang, S.; Jin, H. Inhibition of AURKB, regulated by pseudogene MTND4P12, confers synthetic lethality to PARP inhibition in skin cutaneous melanoma. Am. J. Cancer Res. 2020, 10, 3458-3474.

166. Yamauchi, T.; Uzui, K.; Shigemi, H.; Negoro, E.; Yoshida, A.; Ueda, T. Aurora B inhibitor barasertib and cytarabine exert a greater-than-additive cytotoxicity in acute myeloid leukemia cells. Cancer Sci. 2013, 104, 926-933. [CrossRef] [PubMed]

167. Oser, M.G.; Fonseca, R.; Chakraborty, A.A.; Brough, R.; Spektor, A.; Jennings, R.B.; Flaifel, A.; Novak, J.S.; Gulati, A.; Buss, E.; et al. Cells lacking the RB1 tumor suppressor gene are hyperdependent on aurora B kinase for survival. Cancer Discov. 2019, 9, 230-247. [CrossRef] [PubMed]

168. Yang, D.; Liu, H.; Goga, A.; Kim, S.; Yuneva, M.; Bishop, J.M. Therapeutic potential of a synthetic lethal interaction between the MYC proto-oncogene and inhibition of aurora-B kinase. Proc. Natl. Acad. Sci. USA 2010, 107, 13836-13841. [CrossRef]

169. Diaz, R.J.; Golbourn, B.; Faria, C.; Picard, D.; Shih, D.; Raynaud, D.; Leadly, M.; MacKenzie, D.; Bryant, M.; Bebenek, M.; et al. Mechanism of action and therapeutic efficacy of Aurora kinase B inhibition in MYC overexpressing medulloblastoma. Oncotarget 2015, 6, 3359-3374. [CrossRef] [PubMed]

170. Murai, S.; Matuszkiewicz, J.; Okuzono, Y.; Miya, H.; DE Jong, R. Aurora B Inhibitor TAK-901 Synergizes with BCL-xL Inhibition by Inducing Active BAX in Cancer Cells. Anticancer. Res. 2017, 37, 437-444. [CrossRef]

171. Ou, O.; Huppi, K.; Chakka, S.; Gehlhaus, K.; Dubois, W.; Patel, J.; Chen, J.; Mackiewicz, M.; Jones, T.L.; Pitt, J.J.; et al. Loss-offunction RNAi screens in breast cancer cells identify AURKB, PLK1, PIK3R1, MAPK12, PRKD2, and PTK6 as sensitizing targets of rapamycin activity. Cancer Lett. 2014, 354, 336-347. [CrossRef] [PubMed]

172. Wang, S.; Hwang, E.E.; Guha, R.; O’Neill, A.F.; Melong, N.; Veinotte, C.J.; Saur, A.C.; Wuerthele, K.; Shen, M.; McKnight, C.; et al. High-throughput chemical screening identifies focal adhesion Kinase and Aurora Kinase B inhibition as a synergistic treatment combination in ewing sarcoma. Clin. Cancer Res. 2019. [CrossRef] [PubMed]

173. Tsuno, T.; Natsume, A.; Katsumata, S.; Mizuno, M.; Fujita, M.; Osawa, H.; Nakahara, N.; Wakabayashi, T.; Satoh, Y.; Inagaki, M.; et al. Inhibition of Aurora-B function increases formation of multinucleated cells in p53 gene deficient cells and enhances anti-tumor effect of temozolomide in human glioma cells. J. Neurooncol. 2007, 83, 249-258. [CrossRef]

174. Kumari, S.; Bhattacharya, D.; Rangaraj, N.; Chakarvarty, S.; Kondapi, A.K.; Rao, N.M. Aurora kinase B siRNA-loaded lactoferrin nanoparticles potentiate the efficacy of temozolomide in treating glioblastoma. Nanomedicine 2018, 13, 2579-2596. [CrossRef]

175. Alafate, W.; Wang, M.; Zuo, J.; Wu, W.; Sun, L.; Liu, C.; Xie, W.; Wang, J. Targeting Aurora kinase B attenuates chemoresistance in glioblastoma via a synergistic manner with temozolomide. Pathol. Res. Pract. 2019, 215, 152617. [CrossRef]

176. Borges, K.S.; Castro-Gamero, A.M.; Moreno, D.A.; Da Silva Silveira, V.; Brassesco, M.S.; De Paula Queiroz, R.G.; De Oliveira, H.F.; Carlotti, C.G.; Scrideli, C.A.; Tone, L.G. Inhibition of Aurora kinases enhances chemosensitivity to temozolomide and causes radiosensitization in glioblastoma cells. J. Cancer Res. Clin. Oncol. 2012, 138, 405-414. [CrossRef] [PubMed]

177. Hijjawi, M.S.; Abutayeh, R.F.; Taha, M.O. Structure-Based Discovery and Bioactivity Evaluation of Novel Aurora-A Kinase Inhibitors as Anticancer Agents via Docking-Based Comparative Intermolecular Contacts Analysis (dbCICA). Molecules 2020, 25, 6003. [CrossRef]

178. Khalifa, M.E. Design, synthesis and molecular docking study of new purine derivatives as Aurora kinase inhibitors. J. Mol. Struct. 2021, 1229, 129843. [CrossRef]

179. Al-Sanea, M.M.; Elkamhawy, A.; Paik, S.; Lee, K.; El Kerdawy, A.M.; Syed Nasir Abbas, B.; Joo Roh, E.; Eldehna, W.M.; Elshemy, H.A.H.; Bakr, R.B.; et al. Sulfonamide-based 4-anilinoquinoline derivatives as novel dual Aurora kinase (AURKA/B) inhibitors: Synthesis, biological evaluation and in silico insights. Bioorg. Med. Chem. 2020, 28, 115525. [CrossRef]

180. Fernandes, I..A.; Braga Resende, D.; Ramalho, T.C.; Kuca, K.; Da Cunha, E.F.F. Theoretical Studies Aimed at Finding FLT3 Inhibitors and a Promising Compound and Molecular Pattern with Dual Aurora B/FLT3 Activity. Molecules 2020, $25,1726$. [CrossRef] 